\title{
ALUMNOS ESPAÑOLES EN EL INTERNADO JESUITA DE BEAUMONT (OLD WINDSOR, INGLATERRA), 1880-1886 \\ POR
}

\author{
BERNARDO RODRÍGUEZ CAPARRINI
}

Universidad de Cádiz

\section{RESUMEN}

El presente artículo es continuación de otros tres estudios, en los que en conjunto analizábamos la presencia de alumnos españoles en Beaumont College (Old Windsor, Berkshire, Inglaterra) desde la fundación de este internado jesuita en octubre de 1861 hasta el mes de agosto de 1880. El periodo que ahora estudiamos comprende desde septiembre de 1880 hasta agosto de 1886. Hacemos una relación cronológica de los estudiantes españoles o de ascendencia española que pasan por las aulas del colegio a lo largo de estos seis cursos académicos, aportamos su procedencia geográfica e identificamos a todos ellos.

PALABRAS CLAVE

Alumnos españoles; Beaumont College; Jesuitas ingleses; carlismo.

\section{SPANISH STUDENTS AT BEAUMONT COLLEGE (OLD WINDSOR, ENGLAND), 1880-1886}

\section{ABSTRACT}

The present article is a continuation of three previous studies, in which taken together we analyzed the presence of Spanish students at Beaumont College (Old Windsor, Berkshire, England) from the foundation 
of this Jesuit boarding school in October 1861 until August 1880. The period now under consideration spans from September 1880 to August 1886. The Spanish students, or those of Spanish descent, who passed through the college classrooms over a period of six academic years, are presented chronologically, their geographical origin is given and all of them are identified.

KEY WORDS

Spanish students; Beaumont College; English Jesuits; Carlism.

$\begin{array}{ll}\text { Recibido/Received } & 25-05-2013 \\ \text { Aceptado/Accepted } & 06-06-2014\end{array}$

\section{INTRODUCCIÓN}

El colegio de San Estanislao, más conocido como Beaumont College, fue fundado por la Provincia Inglesa (hoy Británica) de la Compañía de Jesús en Old Windsor (Berkshire, Inglaterra) en octubre de 1861. Con esta fundación a orillas del río Támesis, la orden jesuita sumaba un nuevo internado masculino a los otros dos que ya funcionaban entonces en suelo inglés: Stonyhurst College, establecido en Lancashire en 1794, y Mount St. Mary's College, inaugurado en 1842 en Spinkhill, cerca de Sheffield (Derbyshire). Desde este último año, la Compañía dirigía además en Liverpool un colegio para externos llamado St. Francis Xavier's College. ${ }^{1}$

Hubo alumnos españoles en Beaumont College desde prácticamente el momento de su fundación. Hemos analizado la presencia de alumnos de nacionalidad o ascendencia españolas en Beaumont en tres trabajos anteriores, que en conjunto abarcan el periodo de casi 20 años que va desde la apertura del internado en 1861 hasta

1 Sobre el contexto de la fundación de Beaumont College, véase Rodríguez Caparrini, B. 2004. "El Eton católico": el internado jesuita de Beaumont (Old Windsor, Inglaterra) durante el rectorado del Padre Joseph $M$. Bampton, S.J. (1901-1908): 74-85. Cádiz: Servicio de Publicaciones de la Universidad (edición electrónica de tesis doctoral). 
agosto de $1880 .^{2}$ Frente a los diez estudiantes españoles que ingresaron en Beaumont entre octubre de 1861 y diciembre de 1868, durante el lapso enero de 1869-agosto de 1874 — de inferior duración temporalpudimos contabilizar 24 alumnos de idéntica nacionalidad o ascendencia, mientras que desde septiembre de 1874 hasta agosto de 1880, el número de alumnos españoles admitidos se situó en 11.

El objetivo del presente artículo es relacionar cronológicamente e identificar -en la medida en que las fuentes documentales lo permitana todos los alumnos españoles que se matricularon en Beaumont College desde septiembre de 1880 hasta agosto de 1886. Este periodo, equivalente a seis cursos académicos completos, tiene una duración exactamente igual a la de la etapa $1874-1880$ ya analizada, lo que permite comparar el número y la procedencia de los alumnos españoles en ambas épocas. También estableceremos una comparación con el periodo 1869-1874. Como ya hicimos en los tres estudios precedentes mencionados, incluiremos en nuestro elenco a los jóvenes de nacionalidad o ascendencia españolas y también a aquellos de la misma ascendencia que ya eran ciudadanos británicos o naturalizados en Gran Bretaña en el momento de su ingreso en Beaumont College.

\section{ALUMNOS ESPAÑOLES EN BEAUMONT COLLEGE (1880-1886)}

\section{Curso 1880-1881}

El curso 1879-1880 había finalizado con aproximadamente 170 internos matriculados en Beaumont College. ${ }^{3}$ Cinco de ellos eran españoles o de ascendencia española: Juan Manuel Mitjans Manzanedo, Pedro Pemartín Carrera, Ernesto Larios Sánchez de Piña, Julián de Olivares Ballivián y Juan Osborne Guezala. Al salir definitivamente del internado Ernesto Larios en el verano de 1880, son los cuatro restantes

2 Véase Rodríguez Caparrini, B. 2007. "Alumnos españoles en el internado jesuita de Beaumont (Old Windsor, Inglaterra), 1861-1868". Archivum Historicum Societatis lesu 151: 3-37; Rodríguez Caparrini, B. 2011. "Alumnos españoles en el internado jesuita de Beaumont (Old Windsor, Inglaterra), 18691874". Archivum Historicum Societatis lesu 159: 151-250; Rodríguez Caparrini, B. 2012. "Alumnos españoles en el internado jesuita de Beaumont (Old Windsor, Inglaterra), 1874-1880". Miscelánea Comillas 136: 241-264.

${ }^{3}$ Véase Annual Distribution of Prizes 1873-1914, 3 de agosto de 1880, Londres, Archivum Britannicum Societatis lesu [= ABSI], 5/2/19A. 
los que vuelven a sentarse en las aulas de Beaumont al comenzar el nuevo curso a mediados de septiembre. ${ }^{4}$

Al iniciarse el periodo de nuestro estudio en septiembre de 1880 era rector de Beaumont College el P. Francis Cassidy, S.J. (1845-1915). Natural de Londres, el P. Cassidy había sido profesor en Hodder House -el colegio preparatorio para Stonyhurst College- de 1867 a $1871 .^{5}$ Tras ordenarse sacerdote en septiembre de 1873, fue destinado por motivos de salud a Bournemouth. En 1875 regresó a Hodder como superior, cargo que desempeñó hasta asumir el rectorado de Beaumont el 11 de septiembre de 1877: "Hombre de carácter bondadoso y con gran encanto, llegó a ser conocido como 'el gentil Cassidy', una gentileza que consistía en una mezcla de habilidad y de firmeza, con las que dirigió Beaumont a lo largo de seis años de indudable prosperidad". 6 En septiembre de 1880 forman la comunidad jesuita del colegio otras 32 personas, además del rector Cassidy: 11 sacerdotes, 12 escolares y nueve hermanos coadjutores. Continúan en sus cargos los siguientes jesuitas: William Kenny (1844-1915), Padre ministro y procurator praedii; George R. Kingdon (1821-1893), prefecto de estudios; Robert Whitty (1817-1895), Padre espiritual, anteriormente provincial de Inglaterra (1870-1873); Edward Reeve (1843-1928), prefecto de disciplina. En calidad de viceministro y procurator domus se incorpora - solo durante este curso- el P. Walter Sidgreaves (1837-1919), reputado astrónomo. ${ }^{7}$

${ }^{4}$ El gibraltareño (de ascendencia española) Ernesto Larios Sánchez de Piña debió salir de Beaumont College con posterioridad a su confirmación el 29 de junio de 1880 por el obispo de Southwark, James Danell. A partir de esta fecha no encontramos ninguna referencia a Ernesto Larios en los documentos que emanan de la comunidad jesuita del colegio. Tampoco figura Larios en la relación de alumnos censados en el colegio el 3 de abril de 1881. Véase "General Register Office: 1881 Census Returns", Kew, Surrey, The National Archives, RG11/1325, ff. 114-117, pp. 3-10; Rodríguez Caparrini, B. 2012: 261.

${ }^{5}$ Francis Cassidy tuvo como alumno en Hodder House a Arthur Conan Doyle (1859-1930), quien tras pasar dos años (1868-1870) en el colegio preparatorio, cursó otros cinco (1870-1875) en Stonyhurst College. En su autobiografía, el escritor británico recordará con afecto a Cassidy, "que era más humano de lo que los jesuitas normalmente son”. Conan Doyle, A. 2012. Memories and Adventures: 14. Nueva York: Cambridge University Press. Véase Dudley Edwards, O. 1982. The Quest for Sherlock Holmes: 67-81. Harmondsworth: Penguin.

6 [Bowring, W.] "Reminiscences of Beaumont", c. 1930, ABSI, PQ/4, galerada 2 (documento atribuido a Wilfrid Bowring, alumno de Beaumont College entre 1889 y 1896).

7 Véase "Beaumont status from beginning: compiled by Mr. Sexton", $A B S I, P O / 2$, f. $2^{r}$. 
Académicamente, el colegio estaba dividido en las siguientes clases, o niveles (en orden ascendente): Elements, Figures, Rudiments, Grammar, Syntax, Poetry y Rhetoric. La edad de admisión de los alumnos era, en general, de 8 a 14 años. Se les preparaba para superar el London Matriculation Examination, riguroso examen de ingreso en la Universidad de Londres, que desde 1868 constituía el objetivo académico final de Beaumont College. Normalmente, los internos menores de 10 años eran asignados a la clase de Preparatory o a la de Elements de la domus praeparatoria, un departamento que -ubicado en el edificio más antiguo del colegio (conocido como White House)estuvo a cargo del P. John Lynch, S.J. (1848-1926) durante todo el periodo de nuestro estudio, a excepción del curso 1884-1885.

La llegada de un "Rafael Romero" quedó anotada en el registro de alumnos de Beaumont el 23 de septiembre de $1880 .^{8}$ En la misma fuente podemos leer que Rafael había nacido en "Xerez" (Jerez de la Frontera, Cádiz) el 19 de noviembre de 1867 y que se había educado anteriormente en "Santa María (Cádiz)". Los conocimientos que había

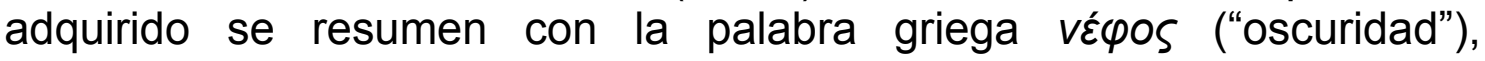
indicándose además que no sabía francés. Por ello, aunque a Romero le faltaban solo dos meses para cumplir los 13 años, se le encuadra en la clase de Figures (11-12 años), donde el profesor era John Proctor, S.J. (1855-1917). El colegio de procedencia de Rafael era concretamente el de San Luis Gonzaga, de El Puerto de Santa María (Cádiz): sabemos que un alumno jerezano llamado Rafael Romero Martínez ingresó interno en este centro de enseñanza de la Compañía de Jesús el 18 de septiembre de 1879 y que salió del mismo el 1 de febrero de 1880, antes de que terminara el curso. ${ }^{9}$ Nos encontramos ante un hijo de Rafael Romero Castañeda (Grazalema c. 1834-Marmolejo 1894) y de Teresa Martínez Sousa (Jerez de la Frontera c. 1844-Madrid 1927), casados en la jerezana iglesia de San Miguel el 28 de octubre de 1864 y padres de otros seis hijos: Juan José (1865-1933), ${ }^{10}$ Consolación, Ángela, Carmen, Rita († Madrid 1926) y Francisco de Paula.

8 "Register of boys admitted into St. Stanislaus' College, Beaumont", ABSI, 5/3/31B.

${ }^{9}$ Véase "Alumnos internos del colegio de San Luis Gonzaga desde su segunda época en 1875 hasta la fecha [1912]". El Puerto de Santa María (Cádiz), Archivo del colegio de San Luis Gonzaga, sin clasificar.

10 Juan José Romero Martínez cursó el bachillerato en el colegio jesuita de San Luis Gonzaga (El Puerto de Santa María), entre 1875 y 1879. Licenciado en Derecho Civil y Canónico por la Universidad de Sevilla y doctor por la Central de Madrid en 1886. Abogado en el bufete del político conservador Francisco Silvela (1845-1905), Juan José Romero militó en el ciervismo, siendo elegido diputado a Cortes por la circunscripción de Jerez de 
Rafael Romero Castañeda era cosechero y almacenista de vinos de Jerez, así como propietario - desde 1873- de una fábrica de aguardientes en dicha ciudad. ${ }^{11}$ Además del alambique jerezano (ubicado en el n. 5 de la calle San José), el Sr. Romero Castañeda tuvo grandes fábricas de destilación y rectificación de espíritu de vino en Valdepeñas (Ciudad Real), Paradas (Sevilla) y Chiclana de la Frontera (Cádiz). También fue representante exclusivo en España para la venta de la harina lacteada y de la lecha condensada de la marca Nestlé. ${ }^{12}$ Compaginó la actividad comercial con los cargos de síndico (administrativo o contencioso) en el Ayuntamiento de Jerez. Incluso llegará a ocupar la alcaldía, interinamente, en noviembre de $1884 .{ }^{13}$

El jueves 18 de noviembre de 1880 —coincidiendo con el día festivo mensual, o Blandyke- ${ }^{14}$ los alumnos representaron Sent to the Tower (1850), farsa en un acto de John M. Morton. Ya a principios del mes de marzo de 1881, durante las fiestas de carnaval, los internos escenifican otras dos farsas: Master's Rival (1829) y B. B. (1860), de Richard B. Peake y Montagu S. Williams/F. C. Burnand, respectivamente.

la Frontera $(1914,1918,1919,1920,1923)$ y designado - 1927- miembro de la Asamblea Nacional Consultiva en representación de "actividades" (sector vitivinícola). Fue subsecretario del Ministerio de Instrucción Pública (marzoagosto de 1921) y ministro interino (24-30 de junio de 1921) de dicho ramo durante la ausencia del titular, Francisco Aparicio Ruiz. Véase "Alumnos internos del colegio de San Luis Gonzaga desde su segunda época en 1875 hasta la fecha [1912]". El Puerto de Santa María (Cádiz), Archivo del colegio de San Luis Gonzaga, sin clasificar; Sánchez de los Santos, M. 1914. Las Cortes Españolas: las de 1914: 652. Madrid: A. Marzo; "Noticias necrológicas". ABC (Madrid), 22 febrero 1933: 34.

${ }^{11}$ Véase Lignon-Darmaillac, S. 2004. Les grandes maisons du vignoble de Jerez (1834-1992): 213. Madrid: Casa de Velázquez.

12 Véase "Sección de anuncios". 1894. Anuario del comercio, de la industria, de la magistratura y de la administración: 47. Madrid: Bailly-Bailliere e Hijos.

${ }^{13}$ Rafael Romero Castañeda será elegido presidente del Casino Liberal Conservador de Jerez en abril de 1893. Cuando fallece en Marmolejo (Jaén) el 1 de mayo de 1894, era vicepresidente de la Cámara de Comercio, Industria y Navegación de Jerez. Véase El Día (Madrid), 21 noviembre 1884: 3; El Orden (Jerez de la Frontera), 19 abril 1893: 1-2; Guía oficial de España 1894: 720. Madrid: Viuda de M. Minuesa de los Ríos; El Guadalete (Jerez de la Frontera), 3 mayo 1894: 3.

${ }^{14}$ El término Blandyke deriva de la villa de Blandecques, donde los jesuitas del colegio de St. Omers (fundado en 1593 en Artois) -convertido luego en Stonyhurst College-comprarían en 1694 una casa de campo para su esparcimiento y el de los colegiales. Véase Gruggen, S.J., G. y Keating, S.J., J. 1901. Stonyhurst. Its Past History and Life in the Present: 14-15. Londres: Kegan Paul, Trench, Trübner \& Co. 
Por su parte, el grupo de teatro de la Asociación de Antiguos Alumnos (Beaumont Union) pone en escena la comedia de George Colman The Heir at Law (1797) y la farsa Sold Again (1876), de Robert Soutar. ${ }^{15}$

Según el censo de población de Gran Bretaña de 1881, confeccionado el 3 de abril, pernoctaron ese día en Beaumont College un total de 187 internos. ${ }^{16}$ Recordemos que cinco de ellos eran españoles 0 de ascendencia española. No habrá nuevas incorporaciones de alumnos españoles durante este curso. Cuando el martes 2 de agosto de 1881 tiene lugar la "Gran Academia" y distribución de premios, el jerezano Pedro Pemartín Carrera —que dejará entonces definitivamente el internado- es el segundo mejor clasificado de su clase de Syntax (11 alumnos). La cifra total de internos se había mantenido en torno a los 186. ${ }^{17}$ El rector Cassidy se desplaza entonces con el grueso de la comunidad jesuita a la población costera de llfracombe (Devon), donde pasan parte de las vacaciones de verano. Regresan a Beaumont el 18 de agosto, el mismo día que el prefecto de disciplina -Edward Reeve- y uno de sus ayudantes parten hacia Ilfracombe con aquellos alumnos que no han marchado a sus casas al terminar el curso. ${ }^{18}$

\section{Curso 1881-1882}

El domingo 14 de agosto de 1881, durante las vacaciones, había ingresado en Beaumont un nuevo estudiante de ascendencia española: en el registro de alumnos del colegio figura como "Cano, Nicolás Salvador Emilio", mientras que el Padre ministro se refiere a él como "Emilio Cano Madrazo". ${ }^{19}$ En el registro se anotan además el lugar y la fecha de su nacimiento (Barcelona, 10 de septiembre de 1869) y los conocimientos adquiridos en su anterior colegio, uno de la ciudad francesa de Lille: "Latín, griego y francés". Con casi 12 años, Cano es asignado a la clase de Elements I (10-11 años), de la que se encargaba

15 Véase Anónimo. 1896. "Complete list of plays, acted at Beaumont from 1862 to 1896". The Beaumont Review 6: 268.

${ }^{16}$ Véase "General Register Office: 1881 Census Returns", Kew, Surrey, The National Archives, RG11/1325, ff. 114-117, pp. 3-10.

17 Véase Annual Distribution of Prizes 1873-1914, 2 de agosto de 1881, ABSI, 5/2/19A; The Tablet (Londres), 6 agosto 1881: 230. La trayectoria posterior de Pedro Pemartín puede verse en Rodríguez Caparrini, B. 2012: 262.

18 Véase "Minister's Journal 1868-1882", 4 y 18 de agosto de 1881, ABSI, 5/1/7.

${ }^{19}$ El Padre ministro añade: "Su padre dice que tramitó su ingreso hace tres o cuatro meses". "Minister's Journal 1868-1882", 14 de agosto de 1881, ABSI, 5/1/7. 
el jesuita John G. Gretton (1856-1904), llamada así para distinguirla de la que se ubicaba en la escuela preparatoria (Elements II). ${ }^{20}$ Pero sabemos que "Emilio Cano" ya se encontraba en Inglaterra desde, al menos, el mes de abril de 1881: en el censo de población de ese año aparece domiciliado en el n. ${ }^{\circ} 19$ de Fitzroy Road -en el municipio londinense de Marylebone- con dos hermanos mayores (Manuel y Julia), "estudiantes" como él, y dos sirvientas. ${ }^{21}$ Podemos identificar a este muchacho como Emilio Cano Hall, hijo del español Manuel Cano [de Diego] Madrazo ( $i-$ Barcelona 1898) y de María Sara Hall Lara (¿ c. 1844-Londres 1881), casados en Guatemala en 1863. Cuando la madre de Emilio Cano fallece de tuberculosis el 16 de marzo de 1881, con 37 años, su marido se encontraba ausente del domicilio, probablemente en Costa Rica, donde era plantador de café. ${ }^{22}$

Manuel Cano Madrazo, había llegado a Guatemala en 1855 desde México con el grado de capitán. Sirve en el ejército guatemalteco durante el mandato del presidente conservador Rafael Carrera (1851-1865) y a comienzos de la presidencia del también conservador Vicente Cerna (1865-1871), llegando a coronel. Tras la reforma liberal, el presidente Miguel García Granados le asciende -24 de julio de 1871- a general de brigada y le nombra comandante general de la zona Centro del país. ${ }^{23}$ Enemistado con el general Justo Rufino Barrios, sucesor de García Granados en 1873, Cano Madrazo emigra a El Salvador, para establecerse pronto en Costa Rica como comerciante. ${ }^{24}$

20 "Register of boys admitted into St. Stanislaus' College, Beaumont", ABSI, 5/3/31B. Emilio Cano no ha podido ser localizado entre los alumnos del colegio jesuita de San José (fundado en Lille en 1872). Comunicación al autor de Robert Bonfils, S.J., director del Archivo de la Provincia de Francia de la Compañía de Jesús (Vanves), 9 de mayo de 2012.

21 Se indica en el censo que tanto Manuel Cano (de 17 años) como su hermana Julia (de 13) habían nacido en América Central. Véase "General Register Office: 1881 Census Returns", Kew, Surrey, The National Archives, RG11/183, f. 5, p. 3.

22 Estos datos constan en el certificado de defunción de "Sara Hall de Cano", emitido por la General Register Office de Inglaterra el 6 de septiembre de 2012, obrante en nuestro poder.

${ }^{23}$ El 3 de septiembre de 1871, Cano Madrazo tuvo que comunicar al superior de la Compañía de Jesús la resolución de García Granados relativa a la expulsión de los jesuitas de la ciudad de Guatemala. En la capital se encontraban ya los miembros de la orden que el mes anterior habían sido expulsados del municipio de Quetzaltenango, en la zona occidental de la República. Véase Miller, H. J. 1969. "The expulsion of the Jesuits from Guatemala in 1871". The Catholic Historical Review 54/4: 640-650.

${ }^{24}$ El 27 de noviembre de 1886, el Gobierno de Costa Rica nombrará a Manuel Cano Madrazo cónsul general de dicha República en Cataluña, puesto 
Originarios del Valle del Pas (Santander), los abuelos paternos de Emilio Cano - Tomás Cano Revuelta y Santa de Diego Madrazofueron comerciantes de textiles en Oviedo. ${ }^{25}$ Por línea materna, Emilio era nieto del comerciante inglés William Hall Mead, quien en 1826 había llegado a Guatemala — desde la posesión británica de Belice, donde fue magistrado- como socio de la casa Hall, Meany \& Bennett. En la ciudad de Guatemala se casa Hall con la autóctona Juliana Lara Corzo (de familia española), siendo nombrado vicecónsul británico en dicha ciudad en 1835 y ejerciendo como cónsul general en funciones desde mayo de 1859 hasta enero de 1862. En octubre de este año asciende a cónsul, cargo que desempeña hasta su muerte en $1865 .{ }^{26} \mathrm{El}$ primogénito de William Hall y de Juliana Lara - tío carnal de Emilio Cano Hall- fue el músico, poeta y traductor Eduardo Hall Lara (Guatemala 1832-Nueva York 1885), que desempeñó los cargos de vicecónsul (1853-1856) y cónsul (1856-1862) de Gran Bretaña en Comayagua (Honduras), así como el de cónsul (1863-?) en Sonsonate (El Salvador). ${ }^{27}$

El ingreso del siguiente alumno español quedó registrado el martes 23 de agosto de 1881: "de Borbon, Jaime". En el registro del colegio se indica que Jaime de Borbón había nacido en Ginebra (Suiza) el 27 de junio de 1870 y que procedía del colegio jesuita de Vaugirard (París), donde había estado escolarizado durante "tres años y medio". Se anota también que el niño se sabía las declinaciones latinas y que hablaba francés. Es destinado a la clase de Elements II, en la escuela preparatoria. $^{28}$ El historiador Román Oyarzun concreta el lugar de

que desempeña hasta su muerte el 14 de junio de 1898. En su nombramiento se indica que Cano Madrazo es "súbdito español, que a su honorabilidad y prudencia reúne las ventajas de conocer este país y de mantener en él relaciones e intereses comerciales". Colección de leyes, decretos, acuerdos y resoluciones. 1887: 603-604. San José, Costa Rica: Imprenta Nacional.

25 Tomás Cano Revuelta fue -en 1864- uno de los socios fundadores del Banco de Oviedo. Al fallecer tres años después, "dejaba propiedades por casi un millón de reales, entre ellas efectos comerciales valorados en 272.000 y créditos por 600.000 reales más". Erice, F. 1995. Propietarios, comerciantes e industriales. Burguesía y desarrollo capitalista en la Asturias del siglo XIX (1830-1885), t. I: 152. Oviedo: Servicio de Publicaciones de la Universidad.

26 Véase Hertslet, E. (compil.). 1865. The Foreign Office List: 94. Londres: Harrison; Naylor, R. A. 1988. Influencia británica en el comercio centroamericano durante las primeras décadas de la Independencia (18211851): 9, 20-22, 107-108, 119-120. Antigua, Guatemala/ South Woodstock, EE.UU.: CIRMA/ Plumsock Mesoamerican Studies.

27 Véase Hertslet, E. 1865: 94; Uriarte, R. 1888. Galería poética centroamericana, t. II: 205-206. Guatemala: Tipografía "La Unión”.

28 Véase "Register of boys admitted into St. Stanislaus' College, Beaumont”, ABSI, 5/3/31B. 
nacimiento de Jaime: "... en la villa de Faraz, sita en la aldea de La Tour de Peilz, ayuntamiento de Vevey (Suiza)". ${ }^{29}$ Este niño de 11 años no es otro que el pretendido infante don Jaime de Borbón Borbón-Parma (el Jaime III de los carlistas), segundogénito y único hijo varón del pretendiente al trono de España don Carlos María de los Dolores de Borbón Austria-Este (Liubliana 1848-Varese 1909) —Carlos VII en la dinastía carlista y primer duque de Madrid- y de la princesa doña Margarita de Borbón-Parma (Lucca 1847-Viareggio 1893). Don Carlos y doña Margarita, casados en Frohsdorf (Austria) el 4 de febrero de 1867, tuvieron además cuatro hijas: Blanca (1868-1949), Elvira (1871-1929), Beatriz (1874-1961) y Alicia (1876-1975).

Don Jaime había pasado sus primeros años en Suiza: primero (1870-1871) en Vevey —cantón de Vaud-y después (1871-1873) en Le Bocage, cantón de Ginebra. En junio de 1873 se traslada con su madre a Francia, a una finca próxima a Burdeos llamada Tartifume. A finales de ese año se mudan a la Ville du Midi, en la ciudad francesa de Pau. En 1874 y 1875 , durante la última guerra carlista (1872-1876), don Jaime llegará a visitar a su padre en el país vasco-navarro. Finalizada la guerra con la derrota de las fuerzas carlistas, don Carlos cruza la frontera franco-española el 28 de febrero de 1876 y emprende poco después un viaje a Estados Unidos y a México, mientras que doña Margarita abandona Pau en el otoño de 1876 para instalarse con sus hijos en París (rue de la Pompe, 49, Passy), donde residirá el matrimonio, "aunque él [don Carlos] en cortas estancias salpicadas de múltiples y prolongadas ausencias". ${ }^{30}$ Debió ser a comienzos del año 1877 cuando D. Jaime consiguió ingresar -como mediopensionista inicialmente- en el reputado colegio jesuita de la Inmaculada Concepción, abierto en 1852 en la parisina calle de Vaugirard: la historiadora Ana de Sagrera reproduce parcialmente una carta de doña Margarita, fechada el 21 de marzo de 1877, de cuyo contenido se deduce que su hijo Jaime era ya entonces alumno de Vaugirard. ${ }^{31}$ Su escolarización aquí durará hasta finales de julio de 1881 , cuando termina los estudios primarios. ${ }^{32}$

${ }^{29}$ Oyarzun, R. 1944. Historia del carlismo: 443. Madrid: Editora Nacional.

30 Vilar, J. B. 2006. La España del exilio. Las emigraciones políticas españolas en los siglos XIX y XX: 295. Madrid: Síntesis.

31 Véase de Sagrera, A. 1969. La duquesa de Madrid (Última reina de los carlistas): 479. Palma de Mallorca: ed. de la autora.

32 Véase Elèves de l'école libre de l'Immaculée Conception à ParisVaugirard, Année 1880-1881. Vanves, Archivo de la Provincia de Francia de la Compañía de Jesús, E Pa 199. Como consecuencia de un decreto de Jules Ferry (29 de marzo de 1880), que daba tres meses de plazo a la Compañía de Jesús para disolverse y abandonar sus establecimientos en Francia, el colegio de Vaugirard quedó bajo el control de un directorio laico a partir de septiembre de 1880. Véase Padberg, S.J., J. W. 1969. Colleges in Controversy. The Jesuit 


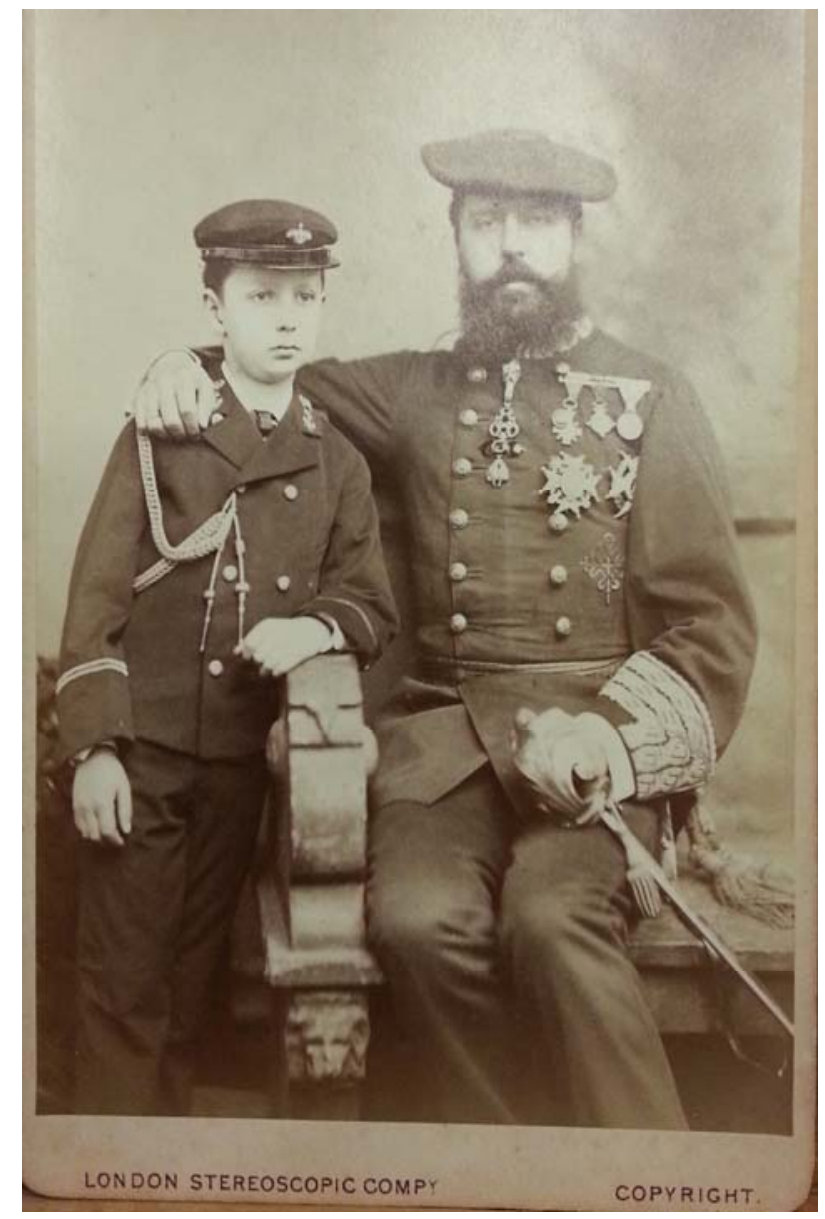

Don Carlos de Borbón con su hijo don Jaime, fotografiados en Londres (enero de 1882). Fuente: Archivo Histórico de Loyola (Compañía de Jesús)

Cuando don Jaime ingresa en Beaumont College el 23 de agosto de 1881, su padre llevaba más de un mes instalado en el hotel Brown de Londres. El duque de Madrid había llegado a la capital inglesa el 18 de julio, tras ser expulsado definitivamente de Francia con motivo de su asistencia a la misa celebrada el día de san Enrique en honor de su tío el conde de Chambord (1820-1883), Enrique $V$ para sus fieles, representante del legitimismo francés, que vivía exiliado en Austria. ${ }^{33} \mathrm{~A}$ poco de llegar a Inglaterra, don Carlos de Borbón manifestaba su intención de que su hijo terminara sus estudios en ese país, "porque admiro y aprecio muchísimo el sistema de educación puesto en práctica

Schools in France from Revival to Suppression, 1815-1880: 265-272. Cambridge, MA: Harvard University Press.

${ }^{33}$ Véase Ferrer, M. 1959. Historia del tradicionalismo español, t. XXVIII, vol. I: 65. Sevilla: Editorial Católica Española. 
en Inglaterra". ${ }^{34}$ De hecho, el sábado 13 de agosto se personará en Beaumont el sacerdote navarro Manuel Fernández de Barrena Aguirrezabala, ${ }^{35}$ preceptor de don Jaime, con objeto de gestionar su ingreso, mientras que seis días más tarde es el propio don Carlos -a quien acompañan cinco personas- el que concluirá los trámites, acordándose que el niño se uniera poco después (lunes 22) al grupo de alumnos que estaba en llfracombe. ${ }^{36}$

El viernes 26 de agosto de 1881 se incorpora a Beaumont como nuevo espiritual el P. James Hayes (1839-1907), simpatizante de la causa carlista, a quien el pretendiente confiará la guarda de don Jaime durante la estancia de este en Inglaterra. ${ }^{37}$ Este curso tienen lugar otros cambios en los cargos directivos del internado: sustituyen a William Kenny los Padres Frederick O'Hare (1850-1925) y Edward Reeve, como ministro y procurador, respectivamente. El antiguo alumno William A. Heathcote (1853-1924), primogénito de un baronet inglés convertido al catolicismo, reemplaza al P. Reeve como prefecto de disciplina. Para sustituir al $P$. Sidgreaves se nombra viceministro a Bernard Vaughan (1847-1922), más tarde célebre predicador, que era sacerdote desde un año antes. ${ }^{38} \mathrm{El}$ ingreso efectivo de don Jaime en Beaumont College tiene lugar el 15 de septiembre de 1881, cuando su padre lo deja en el colegio a cargo de D. Manuel Fernández de Barrena. Este, que ocupa la misma 1881: 2.

34 Anónimo. "Don Carlos en Inglaterra". El Liberal (Madrid), 1 agosto

35 Manuel Fernández de Barrena había sido catedrático en el seminario de Pamplona en 1867-1868, cuando tenía poco más de 20 años. De 1873 a 1876 fue director de personal de "La Caridad", asociación humanitaria para socorro de heridos impulsada y presidida por doña Margarita de Borbón-Parma. Tras la guerra, Barrena emigra a Francia, siendo nombrado ayo de don Jaime y capellán de la casa de Passy (París). Véase Ferrer, M. 1959. Historia del tradicionalismo español, t. XXVI: 33-35. Sevilla: Editorial Católica Española; de Sagrera, A. 1969: 358-360.

${ }^{36}$ Don Jaime y su preceptor fueron acompañados hasta Ilfracombe por el jesuita italiano Estanislao Elviro de Bonis (1857-1917), que había sido profesor de francés en Beaumont College durante el curso 1880-1881. Véase “Minister's Journal 1868-1882", 13, 19 y 22 de agosto de 1881, ABSI, 5/1/7.

37 James Hayes había conocido a don Carlos el 31 de julio de 1874 en el santuario de Loyola (Guipúzcoa), donde ofició ese día su primera misa tras ordenarse sacerdote en el castillo de Poyanne (Francia), principal casa de formación de la provincia jesuita de Castilla en el exilio de 1869 a 1880. EI P. Hayes le dijo entonces al pretendiente que, a pesar de no ser español, era carlista, y que "como tal deseo saludar a Vuestra Majestad". Hayes, S.J., J. 1874. "Visit to the Carlist Country". Letters and Notices 10: 124.

38 Véase "Beaumont status from beginning: compiled by Mr. Sexton", $A B S I, P O / 2$, f. $2^{r}$. 
habitación que el niño en la domus praeparatoria, ${ }^{39}$ deberá darle lecciones de Historia de España y de Historia de la Literatura Española. Puesto que don Jaime no hablaba inglés a su llegada al colegio, se tomó la decisión de emparejarlo inicialmente con otro estudiante llamado Basil Tozer (1868-1949), que dominaba el francés. Tozer recordará en un libro de memorias a su compañero "Jimmy": "Don Jaime me enseñó a fumar cigarrillos. Me cogieron fumando con él y me golpearon con la palmeta. A don Jaime no le golpearon". 40

El 15 de septiembre ingresa también en el internado un español de 9 años -nacido el 28 de enero de 1872, en Madrid- que quedó registrado como "Joseph Gomar". Había ido a un colegio de la capital de España y sus conocimientos eran: "Nada de latín. Poco francés". También será asignado a la clase de Elements II, teniendo como profesor al joven "maestrillo" Bernard Killion (1861-1925). ${ }^{41}$ Se trata de José Pérez-Seoane Villalobos, hijo de José Manuel Pérez-Seoane Marín (Madrid 1847-Madrid 1901) — primer conde de Gomar desde 1875-y de Ángela Villalobos Benavides (¿ c. 1855- ¿ después de 1932). El conde de Gomar acababa de ser elegido, en agosto de 1881, diputado a Cortes - con el partido liberal- por el distrito de Valverde del Camino (Huelva), mientras que su hermano Pablo (Granada 1831-Madrid 1901), segundo conde de Velle (1860), era senador por la provincia de Albacete desde $1877 .{ }^{42}$ El abuelo paterno del niño José Pérez-Seoane, el banquero Manuel Pérez-Seoane Rivero (Sevilla 1802-Madrid 1859), ennoblecido en 1850 con el condado de Velle, había desempeñado —entre otroslos cargos de director general de Montes y de regente de la Audiencia de Manila (1837-1838), siendo nombrado posteriormente senador por la provincia de Cádiz (1844-1845) y vitalicio. ${ }^{43}$ Por línea materna, José era

39 Véase "Minister's Journal 1868-1882", 15 de septiembre de 1881, ABSI, 5/1/7.

40 Tozer, B. 1945. Roving Recollections (Recollections of a Rolling Stone): 9. Londres/ Nueva York: T. V. Boardman.

41 Véase "Register of boys admitted into St. Stanislaus' College, Beaumont", ABSI, 5/3/31B.

42 José Manuel Pérez-Seoane Marín había pertenecido en su juventud a la carrera diplomática. En mayo de 1865 tomó posesión como agregado a la legación de España en Londres, pasando en octubre del año siguiente al mismo puesto en la embajada de Roma. Durante el primer trimestre de 1868, siendo agregado diplomático supernumerario en Roma, se dispuso su pase al Ministerio de Estado en Madrid. Véase Guía diplomática de España para el año de 1865: 297-298. Madrid: Imprenta Nacional; La Época (Madrid), 9 abril 1868: 1.

43 Véase Retana, W. E. 1921. Índice de personas nobles y otras de calidad que han estado en Filipinas desde 1521 hasta 1898: 60. Madrid: 
nieto de Ángel Villalobos Febrer (Vinaroz 1808-Madrid 1880), persona muy vinculada a Inglaterra - profesor de Literatura Española en King's College (Londres) desde 1840 hasta 1847- y, de vuelta en España, diputado a Cortes por los distritos de Manresa (en varias legislaturas, entre 1849 y 1858) y Játiva $(1865-1866) .{ }^{44}$ Es casi seguro que José Pérez-Seoane Villalobos fue acompañado hasta Beaumont College por su madre, que a principios de julio de 1881 había salido de Madrid con destino a Inglaterra, "donde se propone pasar una temporada". ${ }^{45}$

Un nuevo alumno español llegará a Beaumont College el martes 4 de octubre de 1881: "Fernando Osborne". En el registro del colegio se anota que era natural de El Puerto de Santa María (Cádiz), que tenía "11 $3 / 4$ años" y que no había estado escolarizado anteriormente. Fernando era capaz de hacer divisiones largas, pero debido probablemente a que no sabía inglés, se le destina a la clase de Preparatory, cuyo responsable era el escolar jesuita Francis Dobson (1860-1926). ${ }^{46}$ Este niño es Fernando Osborne Guezala, nacido el 5 de enero de 1870 en la portuense calle de San Francisco la Nueva, ${ }^{47}$ tercer hijo varón del bodeguero Tomás Osborne Böhl de Faber (El Puerto de Santa María 1836-Sevilla 1890) y de Enriqueta Guezala Power (Santa Cruz de Tenerife 1840-Sevilla 1910). Recordemos que Juan Osborne Guezala era entonces alumno de Beaumont (desde abril de 1879), mientras que Tomás, su hermano mayor, lo había sido entre 1873 y $1878 .{ }^{48}$ Es

Librería de Victoriano Suárez; Cayuela Fernández, J. 1986. "Manuel Pérez Seoane y Domingo Norzagaray, banqueros madrileños", en L. E. Otero Carvajal y Á. Bahamonde (eds.), Madrid en la sociedad del siglo XIX, vol. 1: 477-489. Madrid: Comunidad de Madrid.

44 Sobre Ángel de Villalobos, véase Gallardo Barbarroja, M. 2003. "Introducción y desarrollo del español en el sistema universitario inglés durante el siglo XIX". Estudios de Lingüística del Español 20 [Documento de Internet disponible en http://ddd.uab.cat/pub/elies/elies a2003v20/index.html] [Fecha de consulta: 27 de diciembre de 2012]; Martínez Gallego, F. A. y Sanz Rozalén, V. 2006. "Villalobos Febrero, Ángel", en J. Paniagua y J. A. Piqueras (dirs.), Diccionario biográfico de políticos valencianos: 1810-2006: 596. Valencia: Institució Alfons el Magnànim.

${ }^{45}$ La Mañana (Madrid), 9 julio 1881: 3. La condesa de Gomar vivirá a partir de entonces separada de su marido, al parecer a causa de que este se batiera en duelo con el actor sevillano Rafael Calvo Revilla (1842-1888). Véase La Lucha (Gerona), 16 marzo 1893: 3.

46 "Register of boys admitted into St. Stanislaus' College, Beaumont", ABSI, 5/3/31B.

${ }^{47}$ Véase Libro de Bautismos, Iglesia Mayor Prioral de El Puerto de Santa María (Cádiz), Libro 146 (1870), ff. 10 y $11^{r}$.

48 Pueden verse más datos familiares de la familia Osborne en Rodríguez Caparrini, B. 2011: 225-228. 
precisamente Tomás Osborne Guezala el que acompaña a Juan y a Fernando hasta Old Windsor ese 4 de octubre, el mismo día que se presentaban en el internado don Carlos y su padre, D. Juan de Borbón Braganza (Aranjuez 1822-Brighton 1887), anterior y discutido pretendiente carlista al trono de España -desde 1861 hasta su abdicación en 1868- como Juan III. Tomás Osborne se alojará en el colegio hasta el viernes 7 de octubre. Un día después, y por invitación del rector Cassidy, don Carlos pernoctará en la habitación que ocupaban su hijo Jaime y el sacerdote Manuel Fernández de Barrena. ${ }^{49}$ El duque de Madrid pasó el domingo 9 en Beaumont: "Recibió una ovación en el patio de recreo y en el comedor de los alumnos. Dos alumnos destacados pidieron un día de vacación. Se marchó por la tarde". 50 A mediados de diciembre de 1881 se alcanza la cifra de 189 alumnos matriculados. El día 20 de ese mes finaliza la construcción de una piscina cubierta, caldeada con vapor, que es bendecida por el P. Cassidy. ${ }^{51}$ Don Jaime de Borbón, acompañado por Manuel Fernández de Barrena, don Carlos (recién recuperado de una bronquitis) y el secretario de este -Francisco Martín Melgar Rodríguez-Carmona (1849-1926)_, pasó la mayor parte de las vacaciones de Navidad en la ciudad costera de Brighton (Sussex): "Hay un aquarium (sic) muy hermoso y un gran baño de agua caliente, y allí nado con papá a las mañanas", ${ }^{52}$ le cuenta al marqués de Cerralbo (Enrique de Aguilera Gamboa, 1845-1922). En opinión de Melgar, "el ilustre discípulo de los jesuitas ha ganado de un modo extraordinario tanto en desarrollo físico como intelectual desde su salida de Francia". 53 El 10 de enero de 1882 se trasladan todos a la mansión de Ashburnham Place (Battle, Sussex). Allí disfrutan durante tres días de la hospitalidad de su propietario, el legitimista inglés lord Bertram Ashburnham (1840-

49 Véase "Minister's Journal 1868-1882", 4, 7 y 8 de octubre de 1881, ABSI, 5/1/7.

${ }^{50}$ Ibídem, 9 de octubre de 1881. Basil Tozer recuerda en sus memorias que cada vez que don Carlos visitaba el colegio, a los alumnos se les instruía para que se portaran y se vistieran lo mejor posible. Véase Tozer, B. 1945: 9.

51 El alumno Charles Albert O'Leary fue el primero en tirarse al agua, completamente vestido. Véase "Minister's Journal 1868-1882", 20 y 21 de diciembre de 1881, ABSI, 5/1/7.

${ }^{52}$ Carta de D. Jaime de Borbón al marqués de Cerralbo, fechada [en Brighton] el 29 de diciembre de 1881. Madrid, Museo Cerralbo, Ms. E. 6490, C. II, n. ${ }^{\circ}$ 2, R. 59.

${ }^{53}$ Carta de F. M. Melgar a El Siglo Futuro, fechada en Brighton el 29 de diciembre de 1881. Reproducida en El Siglo Futuro (Madrid), 2 enero 1882: 2. 
1913), quinto conde de su apellido, converso al catolicismo y representante oficioso de don Carlos en Inglaterra. ${ }^{54}$

Durante las Navidades, algunos internos han representado la farsa My Turn Next (1866), de Thomas J. Williams. Para las fiestas de carnaval del mes de febrero, las piezas elegidas fueron el drama romántico de Thomas E. Wilks The Seven Clerks (1834) y la comedia de Denis O'Bryen A Friend in Need (1783), mientras que el grupo de teatro de los antiguos alumnos puso en escena, con gran éxito, el Macbeth shakesperiano. ${ }^{55}$ El 4 de marzo de 1882 finaliza la estancia en Beaumont College de Manuel Fernández de Barrena, por lo que don Jaime es agregado al dormitorio común de la domus praeparatoria. ${ }^{56}$ Cinco días después -el jueves 9 de marzo- tuvo lugar un acontecimiento especialmente importante en la historia del internado jesuita: la visita de la reina Victoria (1819-1901), que accedió a recibir un homenaje de felicitación por parte de los alumnos con motivo de haber salido ilesa del atentado perpetrado una semana antes por Roderick Maclean en la estación de ferrocarril de Windsor. Aunque el homenaje se desarrolló delante de la entrada principal del colegio, no dentro del recinto, la publicación jesuita Letters \& Notices expresó el siguiente juicio sobre la visita real: "No solo Beaumont resultó honrado por este cumplido de nuestra reina, sino que por medio de él también la Compañía [de Jesús] y los católicos de Inglaterra". ${ }^{57}$ Don Carlos se encontraba ese 9 de marzo en Beaumont College, pues solía visitar a su hijo los jueves y domingos, pero prefirió presenciar la ceremonia desde un discreto segundo plano:

El señor duque de Madrid, exagerando su hidalga delicadeza, no quiso dar pretexto siquiera a malévolas interpretaciones que hubieran podido traer disgustos de mayor o menor cuantía a la soberana reinante, cuya familia tantas pruebas

${ }^{54}$ Véase The Hastings and St. Leonards Observer, 14 enero 1882: 3; Melgar, F. M. "Un católico inglés". El Siglo Futuro (Madrid), 9 febrero 1882: 2. En este artículo, que está fechado en Londres en enero de 1882, Melgar describe a Ashburnham como "entusiasta admirador y amigo fidelísimo" de don Carlos.

55 Entre las aproximadamente 200 personas que asistieron a la representación de la tragedia se encontraba Richard Holt Hutton, crítico literario y editor del semanario londinense The Spectator. En su crítica teatral (The Spectator, 11 marzo 1882: 315), el Sr. Hutton elogió con vehemencia la interpretación de los actores y la valía del $\mathrm{P}$. Bernard Vaughan como director de escena. Véase Ross, S.J., W. 1895. "Annals of the Beaumont stage". The Beaumont Review 4: 152-153.

56 Véase "Minister's Journal 1868-1882", 4 de marzo de 1882, ABSI, $5 / 1 / 7$.

${ }^{57}$ Anónimo. 1882. "Beaumont". Letters and Notices 15: 118. 
de distinción y de afecto prodiga al ilustre desterrado, o a los Padres de Beaumont. ${ }^{58}$

El jueves 16 de marzo de 1882, día festivo en Beaumont College, encontramos de nuevo a don Carlos en el internado, escoltado por su secretario. Tras el almuerzo, el pretendiente, don Jaime y Melgar acompañados por la comunidad jesuita - disfrutaron de una función privada en la que se interpretaron de nuevo las canciones de Macbeth. ${ }^{59}$ Don Carlos regresará al colegio con Manuel Fernández de Barrena el miércoles 5 de abril por la noche, para hacer lo que el Padre ministro definió como un "cuasi-retiro". 60 Se marcha cuatro días después (Domingo de Resurrección), tras haber recibido la comunión "de manos del virtuosísimo preceptor de su hijo en la Misa que este modelo de Sacerdotes celebró y que fue ayudada por don Jaime". 61 A petición de la reina Victoria, como conmemoración de su visita, el rector Cassidy había concedido una prolongación de las vacaciones de Semana Santa, que terminaron el lunes 17 de abril (en vez del jueves anterior). El P. James Hayes aprovechó estos días de descanso para llevar a don Jaime a visitar el palacio de Hampton Court y la ciudad de Londres, así como para remar con él por el río Támesis en las proximidades del colegio. ${ }^{62}$ En esta Semana Santa de 1882 finaliza la estancia de 8 años en Beaumont College de Juan Manuel Mitjans Manzanedo, que un año

58 Anónimo. "Carta de Inglaterra". El Siglo Futuro (Madrid), 13 marzo 1882: 3. En la crónica de la visita que publicó The Daily News también se menciona la presencia de D. Carlos en el colegio aquel día. Véase Anónimo. "The Queen at Beaumont College". The Daily News (Londres), 10 marzo 1882: 3. $5 / 1 / 7$

59 Véase "Minister's Journal 1868-1882", 16 de marzo de 1882, ABSI,

60 Ibídem, 5 de abril de 1882.

61 El Siglo Futuro (Madrid), 12 abril 1882: 2. Véase "Minister's Journal 1868-1882", 9 de abril de 1882, ABSI, 5/1/7. Es probable que durante su retiro, don Carlos, aconsejado por el P. Cassidy, hiciera propósito de enmienda y recibiera la absolución necesaria para poder comulgar. Sería ahora, y no el 7 de junio, víspera de la comunión de su hijo (como asegura Melgar), cuando el pretendiente decidiría poner fin a la relación extramatrimonial que — desde 1877- mantenía con la joven excorista húngara Paula de Somoggy [0 Samoggy] (1860-1917). Véase Martín Melgar, F. 1940. Veinte años con don Carlos. Memorias de su secretario el conde de Melgar: 56-57. Madrid: EspasaCalpe.

62 Véase "Minister's Journal 1868-1882", 11, 15 y 17 de abril de 1882, ABSI, 5/1/7. 
después sucederá a su abuelo materno -Juan Manuel Manzanedo González, 1803-1882 - en el título de duque de Santoña. ${ }^{63}$

El día 27 de abril de 1882, jueves, se celebró en Windsor el matrimonio entre el hijo menor de la reina Victoria, príncipe Leopoldo (1853-1884) —duque de Albany — y la princesa Elena de Waldeck (18611922), por lo que se dio permiso a los internos para alterar su rutina. El carruaje de los recién casados, quienes se dirigían a la residencia de Claremont House (Surrey), se detuvo sobre las 16.45 en la profusamente adornada entrada principal del colegio. Allí esperaban a la real pareja desde casi dos horas antes - la comunidad jesuita con sus educandos y numeroso público. El alumno Alexander J. Codrington (1870-1941), hijo de un baronet británico, fue el elegido para obsequiar a la princesa con un buqué. ${ }^{64}$ Casi un mes más tarde, el 24 de mayo de 1882, la reina Victoria cumplía los 63 años, circunstancia que aprovecharon los alumnos de Beaumont College para pedir un día de asueto. En ausencia del rector, el Padre ministro - Frederick O'Hare- no accedió a la solicitud, aunque sí bebieron a la salud de la reina. ${ }^{65}$

El 2 de junio llegaba a Londres - procedente de su residencia de Viareggio (Italia) - doña Margarita de Borbón-Parma, con sus cuatro hijas, para asistir a la Primera Comunión de don Jaime. Desde ese mismo día quedan instaladas con don Carlos en The Priory, una histórica casa de Old Windsor próxima al colegio que el duque de Madrid había alquilado a la familia Romaine. ${ }^{66}$ La ceremonia religiosa tuvo lugar el 8 de junio de 1882, día de Corpus, comenzando a las 7 de la mañana. Entre los 19 comulgantes se encontraban, además de don Jaime, los españoles Emilio Cano Hall y José Pérez-Seoane Villalobos. ${ }^{67}$ Ofició la misa el rector Cassidy, asistido por Manuel Fernández de Barrena, el P.

${ }^{63}$ Véase su trayectoria posterior en Rodríguez Caparrini, B. 2011: 245.

64 Véase "Minister's Journal 1868-1882", 27 de abril de 1882; The Standard (Londres), 28 abril 1882: 5-6.

65 Véase "Minister's Journal 1868-1882", 24 de mayo de 1882, ABSI, $5 / 1 / 7$.

${ }^{66}$ Ibídem, 2 de junio de 1882.

67 Véase "Beaumont First Communions, Confirmations, etc.", 8 de junio de 1882, ABSI, 5/2/17. Comulgaron también don Carlos, doña Margarita y su hija Blanca. Con motivo de la comunión de don Jaime hubo aparentemente una reconciliación entre sus padres, aunque los duques de Madrid no convivirán después de este encuentro en Inglaterra. En 1880 habían circulado rumores sobre una inminente separación del matrimonio. Véase Canal, J. 2010. "Incómoda presencia: el exilio de don Carlos en París", en F. Martínez, J. Canal y E. Lemus (eds.), París, ciudad de acogida. El exilio español durante los siglos $X I X$ y $X X:$ 110-111. Madrid: Sociedad Estatal de Conmemoraciones Culturales/Marcial Pons Historia. 
Hayes y los duques de Madrid. Junto con el secretario de don Carlos, estuvieron en Beaumont College ese día otros personajes carlistas como la baronesa Emma von Reischach, el conde de la Rad de Varea (José María de Lasuen), la condesa de Caltavuturo (Emily Mildred de Potestad Chapman), el marqués de Villadarias (Francisco Javier Fernández de Henestrosa Santisteban) y el general Isidoro de Iparraguirre. ${ }^{68}$ A las 2 de la tarde llega al internado el influyente líder católico Henry FitzalanHoward (1847-1917) -decimoquinto duque de Norfolk - con su esposa (lady Flora Hastings, 1854-1887) y una de las hermanas del duque. Tras almorzar con los PP. Cassidy, Vaughan y Lynch, los Norfolk participan en la procesión de Corpus junto con el grupo de carlistas. Más tarde comparten con ellos la merienda que se les preparó en una de las salas del colegio. ${ }^{69}$ La duquesa de Madrid, sus hijas y el séquito se marchan de Inglaterra el 14 de junio: el $P$. Hayes acompaña a don Jaime a la estación de Charing Cross para la despedida, regresando ambos a Beaumont por la noche. Don Carlos, que no abandona todavía Inglaterra, regalará al colegio "dos espléndidos y magníficos misales, verdaderas joyas de arte"70 como recuerdo de la comunión de su hijo.

Después de 13 años de suspensión, el jueves 27 de julio de 1882 se enfrentan -y empatan - en el campo de críquet del internado jesuita los equipos de Beaumont College y del Oratory School de Edgbaston (Birmingham), figurando entre los jugadores del equipo anfitrión el español Julián de Olivares Ballivián." Ese mismo día, "el P. Torre, Visitador de España, con los PP. Granero y Di Pietro y un hermano español vinieron a ver el colegio. También Père Mazoyer, un Padre francés. Todos se marcharon por la tarde". ${ }^{72}$ Poco después, el martes 1

${ }^{68}$ Véase "Minister's Journal 1868-1882", 8 de junio de 1882, ABSI, 5/1/7; Anónimo. "Noticias de Inglaterra". El Siglo Futuro (Madrid), 12 junio 1882: 2. Ni en el diario del Padre ministro ni en la crónica del diario integrista El Siglo Futuro se hace mención de la presencia de don Juan de Borbón Braganza en el colegio, si bien Martín Melgar asegura que el abuelo de don Jaime "no vaciló en venir desde las cercanías del Polo, donde estaba cazando, hasta Londres para asistir a la comunión de su nieto". Martín Melgar, F. 1940: 56.

${ }^{69}$ Véase "Minister's Journal 1868-1882", 8 de junio de 1882, ABSI, 5/1/7.

70 Anónimo. "Noticias de Inglaterra". El Siglo Futuro (Madrid), 19 junio 1882: 2. Véase "Minister's Journal 1868-1882", 14 de junio de 1882, ABSI, $5 / 1 / 7$.

71 Véase "Ignotus" [Bowring, W.]. 1926. Beaumont v. Oratory, 18671925: 10-11. Windsor: Robert Brodie \& Son.

72 “Minister's Journal 1868-1882", 27 de julio de 1882, ABSI, 5/1/7. Los jesuitas nombrados son los españoles Juan José de la Torre (1830-1915) y Juan de la Cruz Granero (1848-1917), el italiano Giovanni Battista di Pietro (1820-1883) y el lionés Pierre Mazoyer (1840-1918). 
de agosto, tiene lugar la distribución anual de premios. Entre los aproximadamente 320 invitados se encontraba don Carlos de Borbón. El acto fue presidido por Mons. John Virtue (1826-1900), flamante obispo de la diócesis de Portsmouth. Uno de los estudiantes premiados de la clase de Grammar - compuesta por 19 alumnos - fue Julián de Olivares, cuya estancia en el colegio finalizó entonces, mientras que el jerezano Rafael Romero Martínez obtuvo también su galardón en la clase de Figures (30 alumnos). El número de internos matriculados en Beaumont College al terminar el curso $1881-1882$ ascendía a $188 .^{73} \mathrm{El} 11$ de agosto sale también definitivamente del colegio Emilio Cano Hall, tras una estancia de solo un curso. ${ }^{74}$ Por su parte, don Jaime de Borbón y su padre acompañados por Melgar, Fernández de Barrena y el jesuita James Hayes - viajan este verano de 1882 por Bélgica, Austria e Italia. A partir del otoño, D. Carlos establecerá su residencia definitiva en el palacio veneciano de Loredán, herencia de su madre la archiduquesa María Beatriz de Austria-Este (1824-1906). ${ }^{75}$

\section{Curso 1882-1883}

El nuevo curso da comienzo, el lunes 18 de septiembre de 1882, sin apenas cambios en los cargos directivos de Beaumont College. La única novedad es la incorporación como viceministro del $P$. William Kenny, en sustitución de Bernard Vaughan, que hará este año la tercera probación en Manresa House, Roehampton. La comunidad jesuita del colegio la componen 33 personas: ocho sacerdotes, 14 escolares y 11 hermanos coadjutores. ${ }^{76}$

73 Véase "Minister's Journal 1868-1882", 1 de agosto de 1882, ABSI, 5/1/7; Annual Distribution of Prizes 1873-1914, 1 de agosto de 1882, ABSI, 5/2/19A. La trayectoria posterior de Julián de Olivares Ballivián, en Rodríguez Caparrini, B. 2012: 263.

74 “Minister's Journal 1868-1882", 11 de agosto de 1882, ABSI, 5/1/7. Emilio Cano Hall se establecerá en San José (Costa Rica), donde se casará con Rafaela de Castro Hernández-Pinzón (que fallecerá, ya viuda, el 25 de agosto de 1952). A finales de 1900, Cano Hall formó en Barcelona con Carlos Fortuny Miralles, durante 10 años, una sociedad dedicada a la fabricación y venta de licores. Al dar la noticia de su asociación en 1919 con la empresa licorera Hijos de Juan Suau, de Palma de Mallorca, la revista Baleares (10 junio 1919: 14) se refiere a Emilio Cano como "ingeniero agrónomo y notable licorista". Véase "Registro Mercantil e Industrial". Revista llustrada de Banca, Ferrocarriles, Industria y Seguros, 10 noviembre 1900: 19; "Necrológicas. Doña Rafaela de Castro, viuda de Cano". ABC (Sevilla), 28 agosto 1952: 16. 1940: 68.

75 Véase The Tablet (Londres), 5 agosto 1882: 221; Martín Melgar, F.

76 Véase "Beaumont status from beginning: compiled by Mr. Sexton", $\mathrm{ABSI}, \mathrm{PO} / 2$, f. $2^{\mathrm{r}}$. 
Don Jaime de Borbón y el $P$. Hayes llegan a Old Windsor, procedentes de Viareggio, el primer día de curso. ${ }^{77}$ Otros cuatro alumnos españoles continúan sus estudios en Beaumont: Rafael Romero Martínez, José Pérez-Seoane Villalobos, Juan Osborne Guezala y Fernando Osborne Guezala. Un hermano de estos dos últimos ingresará el domingo 8 de octubre: se trata de Roberto, nacido en El Puerto de Santa María (Cádiz) el 15 de abril de 1873. En el registro del colegio se indica también que Roberto Osborne Guezala no había estado escolarizado antes de su llegada al internado jesuita y que no hablaba inglés. Como -además- tenía 9 años, se le asigna a la clase de Preparatory, que estaba a cargo de Frederick Akehurst, S.J. (18591895). ${ }^{78}$ Roberto, Fernando y Juan Osborne Guezala llegan a Beaumont College acompañados por el hermano mayor -Tomás- y por el padre de todos ellos, Tomás Osborne Böhl de Faber, quienes permanecen en Inglaterra al menos hasta el 10 de octubre, día de asueto por conmemorarse el vigésimo primer aniversario de la fundación del colegio. ${ }^{79}$ Según refiere el notario sevillano Cástor Montoto (1892-1981), Roberto Osborne descubrió —recién llegado a Beaumont- unas granadas en la despensa del internado. Cuando quiso cogerlas, un hermano jesuita se lo impidió diciéndole que eran del "príncipe" don Jaime, que en ese momento avanzaba por el pasillo: "-'Tú eres príncipe?' -'Mi padre es el rey don Carlos de Borbón' -‘¡Ah, don Carlos!...'. Quedaron muy amigos, y a los pocos días, en la intimidad, don Jaime les anunciaba: "Cuando yo sea rey, tú, Juanito, serás gobernador, y tú, Roberto, ministro". 80

No hay nuevas incorporaciones de alumnos españoles o de ascendencia española en este curso. Justo un mes después del ingreso de Roberto Osborne Guezala, el P. O'Hare anotó en su diario el del londinense James John Lindley, con lo que el número de alumnos matriculados se elevó a $191 .^{81}$ El obispo John Virtue se alojará en el colegio entre el 11 y el 14 de noviembre de 1882, coincidiendo con la festividad del patrono, san Estanislao. ${ }^{82}$ El 2 de diciembre, el rector

77 Véase "Minister's Journal 1868-1882", 18 de septiembre de 1882, ABSI, 5/1/7.

78 Véase "Register of boys admitted into St. Stanislaus' College, Beaumont", ABSI, 5/3/31B.

${ }^{79}$ Véase "Minister's Journal 1868-1882", 10 de octubre de 1882, ABSI, $5 / 1 / 7$.

80 Montoto de Sedas, C. "Don Jaime. El príncipe sencillo". Semana (Madrid), 13 octubre 1959: 20. $5 / 1 / 7$.

${ }^{81}$ Véase "Minister's Journal 1868-1882", 8 de noviembre de 1882, ABSI,

${ }^{82}$ Véase Ibídem, 11 y 14 de noviembre de 1882. 
Cassidy -acompañado por un antiguo alumno (Humphrey F. de Trafford) y otro actual (Charles M. Wood)- se desplaza en un landó hasta el Castillo de Windsor con objeto de recibir el retrato enmarcado de la reina Victoria, con su autógrafo, que esta había regalado para conmemorar su visita del mes de marzo anterior. La ceremonia de presentación del cuadro, a la que asiste el colegio en pleno, tiene lugar en el refectorio del internado el 8 de diciembre. Tras un breve discurso del P. Cassidy, "los alumnos congregados dieron vítores entusiásticos a Su Majestad". 83 EI 19 de diciembre, don Jaime de Borbón parte hacia Italia, en compañía una vez más - del jesuita James Hayes, para pasar las vacaciones con sus padres y hermanas: la Navidad en Florencia, el Año Nuevo en Viareggio y el día de Reyes en Venecia. ${ }^{84}$ Ambos regresan a Old Windsor el sábado 13 de enero de 1883, trayendo consigo "a un sacerdote español que se queda aquí algunos días". ${ }^{85}$ A finales de ese mismo mes se presenta en el colegio Tomás Osborne Guezala para visitar a sus tres hermanos. ${ }^{86}$ Ya en la segunda semana de febrero, en carnaval, los alumnos representan el drama de James Sheridan Knowles William Tell (1825) y la farsa Done on Both Sides (1847), de John M. Morton. Por su parte, los actores de la Asociación de Antiguos Alumnos ponen en escena el drama histórico en verso blanco Richelieu (1839), de Edward G. Bulwer-Lytton. ${ }^{87}$ Poco después se desencadena en Beaumont una epidemia de sarampión de trágicas consecuencias: el 27 de febrero fallece el alumno irlandés de 15 años George McGrath, mientras que cuatro días más tarde morirá, con la misma edad, su compañero londinense Wilfred Heeley. Ese 3 de marzo de 1883 -que pasará a la historia del colegio como "Sábado Negro"- hubo que lamentar además la caída, desde una altura de 6 metros, del interno de Preparatory Charles Ferguson, mientras se deslizaba por el pasamanos de la escalera principal de la White House. Aunque permaneció inconsciente durante 36 horas, Ferguson pudo salvar la vida. ${ }^{88}$ La virulencia del brote de sarampión -69 alumnos contagiados- obligó al rector a anticipar el inicio

83 Anónimo. 1897. "The Queen and Beaumont", The Beaumont Review Número especial: 8. Véase "Minister's Journal 1868-1882", 2 de diciembre de 1882, ABSI, 5/1/7; Anónimo. "The Queen”. The Times (Londres), 9 diciembre 1882: 9.

${ }^{84}$ Véase "Minister's Journal 1868-1882", 19 de diciembre de 1882, ABSI, 5/1/7; "Noticias de Venecia". El Siglo Futuro (Madrid), 15 enero 1883: 1.

85 “Minister's Journal 1883-1891", 13 de enero de 1883, ABSI, 5/1/8.

${ }^{86}$ Ibídem, 29 de enero de 1883.

87 Véase Ross, S.J., W. 1895. "Annals of the Beaumont stage". The Beaumont Review 4: 154.

${ }^{88}$ Véase "Minister's Journal 1883-1891", 3 y 6 de marzo de 1883, ABSI, 5/1/8; Heathcote, S.J., W. 1940. "Reminiscences of School Life in the Early Days of Beaumont", The Beaumont Review 160: 382. 
de las vacaciones de Semana Santa al 6 de marzo, día en que don Jaime marcha a Viareggio con el $P$. Hayes. No regresarán a Inglaterra hasta el lunes 9 de abril, la fecha de reinicio de las clases indicada en la circular que el P. Cassidy dirige a las familias en la semana de Pascua. ${ }^{89}$

El jueves 7 de junio de 1883, el equipo de críquet de Beaumont se enfrenta al Marylebone Cricket Club, "pero por falta de tiempo no se pudo terminar el partido". ${ }^{90}$ El día 23 de ese mes -sábado- pernoctará en Beaumont College el mayor de los hermanos Osborne Guezala, Tomás, que asistirá dos semanas después a la cena anual de la Asociación de Antiguos Alumnos. ${ }^{91}$ El martes 24 de julio tiene lugar el partido de críquet entre el equipo del internado jesuita y el del Oratory School, con resultado de empate. En la capital del Imperio británico pasará su onomástica don Jaime de Borbón, acompañado por el P. Hayes. ${ }^{92}$ El día siguiente -26 de julio- concederá vacación el rector "para conmemorar el éxito de los que han aprobado el examen de ingreso en la Universidad de Londres". ${ }^{93} \mathrm{Y}$ es que los alumnos de la clase de Rhetoric Francis J. Hannan y Thomas Woodlock habían obtenido respectivamente el primer y cuarto puesto en la lista, de entre los 554 aspirantes que aprobaron el London Matriculation en la convocatoria de junio de ese año. El diario The Times apostilló al dar la noticia: "Es la primera vez que un colegio católico romano ocupa el primer lugar". ${ }^{94}$

El miércoles 1 de agosto de 1883 tiene lugar la tradicional Academia de fin de curso, que preside un año más el obispo John Virtue. En la distribución de premios, el jerezano Rafael Romero Martínez ${ }^{95}$ fue

${ }^{89}$ Véase "Minister's Journal 1883-1891", 9 y 28 de marzo y 9 de abril de 1883, ABSI, 5/1/8; El Siglo Futuro (Madrid), 9 abril 1883: 2.

90 The Tablet (Londres), 16 junio 1883: 950.

91 En esta ocasión, la cena no se celebró - como de costumbre- en Londres, sino en el mismo colegio. Véase "Minister's Journal 1883-1891", 23 de junio y 8 de julio de 1883, ABSI, 5/1/8.

92 Véase "Ignotus" [Bowring, W.]. 1926: 12-13; "Minister's Journal 18831891", 25 de julio de 1883, ABSI, 5/1/8.

93 "Minister's Journal 1883-1891", 26 de julio de 1883, ABSI, 5/1/8.

94 Anónimo. "University of London". The Times (Londres), 16 julio 1883: 6. En la convocatoria de junio de 1883 se presentaron a este examen 932 aspirantes (5 pertenecían a Beaumont College), que debían tener como mínimo 16 años de edad. Véase Anónimo. 1884. "London University Examinations". Letters and Notices 17: 72-73.

${ }^{95}$ Rafael Romero sale ahora definitivamente del colegio. Desconocemos si prosiguió estudios en España o en otro país. Tras la muerte de su padre en 1894, continuará el negocio familiar de vinos asociado con su madre y hermanos. El 11 de febrero de 1899 se casará con Enriqueta Rodil Díaz, con 
el segundo de su clase de Rudiments (26 alumnos), mientras que Juan Osborne Guezala -que pertenece a la clase de Elements I (32 alumnos)obtuvo un galardón en "puntos globales" (aggregate of marks). ${ }^{96}$ Asistieron unos 300 invitados, entre los que se encontraban el obispo auxiliar de Westminster (James L. Patterson), el alcalde de Windsor (Joseph Devereux), lord Braye (Alfred Verney-Cave), lord Ashburnham, lady Bulkeley (Maria-Frances Stanley), el barón austríaco Adhémar de Linden, el legitimista francés Guillaume de Bourgade (conde de Bourgade), el coronel George Howard-Vyse y el canónigo Augustus Applegath. El almuerzo posterior fue amenizado por la banda del regimiento 4th Queen's Own Hussars. ${ }^{97}$

\section{Curso 1883-1884}

El nuevo curso da comienzo el 12 de septiembre de 1883, miércoles. Don Jaime regresa al colegio con el $\mathrm{P}$. Hayes sobre las $11 \mathrm{de}$ la noche del día siguiente. ${ }^{98}$ Diez días antes, el hijo de don Carlos había asistido a la ceremonia del traslado hasta el panteón familiar de Gorizia de los restos del conde de Chambord, fallecido en su residencia austríaca de Frohsdorf el 24 de agosto:

El Sr. D. Juan de Borbón, llegado de Inglaterra la víspera, ocupaba el centro del duelo, llevando a su derecha al señor duque de Parma y a su izquierda al gran duque de Toscana. D. Carlos seguía en el segundo centro con $D$. Alfonso y $D$. Jaime, y detrás don Miguel de Braganza y el príncipe Luis de Baviera. ${ }^{99}$

Durante este curso, el último del $\mathrm{P}$. Francis Cassidy como rector, componen la comunidad jesuita de Beaumont College 34 personas: diez sacerdotes, 12 escolares y 12 hermanos coadjutores. El P. Frederick O'Hare hará este año la tercera probación, por lo que el cargo de ministro lo desempeñará el P. George Dover (1851-1925), Master of Arts (Exeter College, Oxford), convertido al catolicismo en 1872. Como William Heathcote inicia sus estudios de teología en la casa de formación

quien no tendrá hijos. Romero Martínez fallecerá en Jerez de la Frontera el 19 de agosto de 1905. Véase El Guadalete (Jerez de la Frontera), 12 febrero 1899: 2; El Guadalete (Jerez de la Frontera), 19 agosto 1905: 3.

${ }^{96}$ Véase Annual Distribution of Prizes 1873-1914, 1 de agosto de 1883, ABSI, 5/2/19A. El curso 1882-1883 finalizó con 182 alumnos.

97 Véase Anónimo. "Beaumont College, Old Windsor". The Slough, Eton and Windsor Observer, 4 agosto 1883: 2-3.

98 Véase "Minister's Journal 1883-1891", 13 de septiembre de 1883, ABSI, 5/1/8. 1883: 1 .

${ }^{99}$ Anónimo. "Carta de Goritz". El Siglo Futuro (Madrid), 10 septiembre 
francesa de Mold (Gales), la prefectura de disciplina es asumida por el P. Patrick Hogan (1846-1904). ${ }^{100}$

De los cinco estudiantes españoles que continúan en Beaumont, Juan Osborne Guezala y José Pérez-Seoane Villalobos han pasado a la clase de Figures, mientras que los tres restantes -D. Jaime de Borbón y los hermanos Fernando y Roberto Osborne Guezala - coinciden en la inmediatamente inferior de Elements. El jesuita que confeccionó el registro de alumnos anotó el 7 de octubre de 1883 el ingreso de "Carlos Larios y Sánchez", indicando que había nacido en Gibraltar en octubre de 1870 , que su colegio de procedencia era uno de la colonia británica y que no sabía ni latín ni francés. Con 13 años, Larios es asignado a la clase de Elements II, de la que se encargaba el jesuita irlandés Matthew Toohey (1854-1926). ${ }^{101}$ Se trata de Carlos Larios Sánchez de Piña, hermano de los cuatro Larios -Pablo, Leopoldo, Augusto y Ernesto- que ya habían recibido parte de su educación en Beaumont College. Carlos Larios era, por tanto, el menor de los seis hijos (uno había muerto de niño) de Pablo Antonio Larios Tashara (1819-1879) y de Leocadia Sánchez de Piña (c. 1831-1919), casados en Gibraltar en 1861. Puede considerarse al riojano Pablo Eustaquio Larios Herreros (Laguna de Cameros 1793-Gibraltar 1869), abuelo paterno de los Larios Sánchez de Piña, como fundador de la dinastía gibraltareña y del Campo de Gibraltar de los Larios. ${ }^{102}$

El penúltimo domingo del mes de octubre llega al colegio Tomás Osborne Böhl de Faber para pasar la jornada con sus tres hijos. ${ }^{103} \mathrm{El} \mathrm{P}$. Hayes llevará a don Jaime a Londres el 11 y el 17 de diciembre (el último de estos días para una visita al médico). Carlos Larios marcha a Escocia el 19 de diciembre, mientras que al día siguiente James Hayes, S.J. y don Jaime emprenden de madrugada su habitual viaje a Italia. ${ }^{104} \mathrm{El}$

100 Véase "Beaumont status from beginning: compiled by Mr. Sexton", $\mathrm{ABSI}, \mathrm{PO} / 2$, f. 2'; Gordon Gorman, W. 1910. Converts to Rome: 89. Londres: Sands \& Co; Anónimo. 1925. "Obituary. Father William Heathcote". Letters and Notices 40: 64-65.

101 Véase "Register of boys admitted into St. Stanislaus' College, Beaumont", ABSI, 5/3/31B.

102 Sobre la familia Larios y la estancia en Beaumont de los cuatro hermanos Larios Sánchez de Piña, véase Rodríguez Caparrini, B. 2012: 248250, 253, 259-262.

103 Véase "Minister's Journal 1883-1891", 21 de octubre de 1883, ABSI, $5 / 1 / 8$

${ }^{104}$ El P. Hayes acompañó ese 20 de diciembre, suponemos que hasta Londres, a los alumnos José Pérez-Seoane Villalobos, John Edmund Garratt Gardner (1869-1935), su hermano Hilary (1870-1956) y Arthur N. Pazolt (1869- 
jueves 10 de enero de 1884, al final de las vacaciones de Navidad, algunos alumnos que han permanecido en el colegio representan las farsas A Spanking Legacy (1843), de Thomas G. Blake, y Cherry Bounce (1821), de Richard J. Raymond. Dos días después regresan a Beaumont don Jaime de Borbón y José Pérez-Seoane, acompañados por el $P$. Hayes. ${ }^{105}$

El Blandyke del jueves 21 de febrero de 1884 se celebra por la mañana con el primero de los tres partidos (Grand Matches) que pondrán fin a la temporada futbolística. Tras el almuerzo, los internos llevan a escena con gran éxito la comedia en cinco actos de George Colman The Poor Gentleman (1802) y la farsa A Sudden Arrival (1866), de Frederick Hay. Poco después, el lunes y martes de carnaval ( 25 y 26 de febrero), los actores de la Asociación de Antiguos Alumnos escenifican el popular melodrama de Tom Taylor The Ticket-of-Leave Man (1863) y la farsa de Joseph Lunn Fish out of Water (1823), mientras que los alumnos optan por la opereta de H. B. Farnie Retained on Both Sides (1875), adaptación de la original compuesta en 1869 por el francés Charles Lecocq. ${ }^{106}$ Para amenizar el Blandyke de marzo (día 13) hubo otra función teatral de los internos, que consistió en la comedia de Charles Reade The Robust Invalid (1870) -adaptación de Le Malade Imaginaire, de Molière- y en The Blind Beggars (1882), versión inglesa de una opereta de Jacques Offenbach. ${ }^{107} \mathrm{~A}$ finales de ese mes se celebran en el colegio diversas carreras y concursos de atletismo. En la prueba de velocidad de 220 yardas (200 metros lisos), en la categoría júnior, venció Carlos Larios Sánchez de Piña (que empleó 30 segundos), quedando subcampeón John W. Darwood. ${ }^{108}$ Tuvo que ser durante este curso 1883-1884 cuando don Jaime de Borbón se vio obligado a participar en un "duelo" de boxeo en defensa de Carlos Larios ("Larrios" le llama Francisco Melgar hijo): "El combate fue rudo, pues él [D. Jaime] ignoraba aún por completo las

1943). Véase "Minister's Journal 1883-1891", 11, 17, 19 y 20 de diciembre de 1883, ABSI, 5/1/8.

${ }^{105}$ Véase Ibídem, 10 y 12 de enero de 1884; Anónimo. 1896. "Complete list of plays, acted at Beaumont from 1862 to 1896". The Beaumont Review 6: 268.

106 Véase "Minister's Journal 1883-1891", 21, 25 y 26 de febrero de 1884, ABSI, 5/1/8.

107 Véase "Minister's Journal 1883-1891", 13 de marzo de 1884, ABSI, 5/1/8; Digby Beste, S.J., K. 1908. "List of Plays Acted at Beaumont from 18621908". The Beaumont Review 55: 395.

108 Véase "Minister's Journal 1883-1891", 25 y 27 de marzo de 1884, ABSI, 5/1/8; Anónimo. "Athletic Sports at Beaumont College". The Slough, Eton and Windsor Observer, 29 marzo 1884: 3. 
reglas, pero se batía como un león animado por la justicia de la causa y deseoso de dejar en buena postura el nombre de España". ${ }^{109}$

Al tenerse noticia de la muerte del príncipe Leopoldo de Gran Bretaña, acaecida en Cannes (Francia) el 28 de marzo de 1884, desde Beaumont College se enviaron sendas cartas de pésame a la reina Victoria y a la duquesa viuda de Albany. Justo una semana después se dio permiso a los alumnos para asistir al funeral en Windsor. El Martes Santo (8 de abril), víspera del comienzo oficial de las vacaciones de Semana Santa, don Jaime de Borbón y el P. Hayes marchan a la mansión de lord Ashburnham, de donde regresarán el día fijado para la incorporación de los alumnos (17 de abril). ${ }^{110}$ En el boletín de calificaciones de Roberto Osborne Guezala correspondiente al segundo trimestre del curso consta que este portuense ocupaba el puesto decimoquinto de su clase de Elements (21 alumnos). El P. Cassidy hizo las siguientes observaciones: "Conducta buena. Aplicación y atención en clase, ambas buenas. Un muchacho bueno y agradable, con resultados satisfactorios". ${ }^{111}$ En el informe escolar de Juan Osborne Guezala podemos leer que se había clasificado en undécimo lugar de los 33 alumnos que formaban la clase de Figures. Después de alabar la conducta y la aplicación de Juan Osborne, el rector anotó que el muchacho se había distinguido en los exámenes de ese trimestre. ${ }^{112} \mathrm{El}$ martes 29 de abril se presenta en el internado jesuita Ángela Villalobos (condesa de Gomar) para visitar a su hijo José Pérez-Seoane. Una semana después, el 5 de mayo, es doña Margarita de Borbón-Parma la que llega a Old Windsor, alojándose con lady Bulkeley en su residencia de Pelling Place. ${ }^{113}$ La duquesa de Madrid irá el lunes siguiente por la tarde al castillo de Windsor para visitar a la reina Victoria, que envió un carruaje al colegio: "La duquesa estuvo con su majestad casi dos horas,

109 Melgar [Trampus], F. 1932. Don Jaime. El Príncipe caballero: 33. Madrid: Espasa-Calpe.

110 Véase "Minister's Journal 1883-1891", 3, 4, 8 y 17 de abril de 1884, ABSI, 5/1/8.

111 “A. M. D. G. St. Stanislaus' College. Beaumont. Report of Examinations, $2^{\text {nd }}$ Term 1883-4. Robert Osborne". El Puerto de Santa María (Cádiz), Archivo de Tomás Osborne Gamero-Cívico, sin clasificar.

112 “A. M. D. G. St. Stanislaus' College. Beaumont. Report of Examinations, $2^{\text {nd }}$ Term 1883-4. John Osborne". El Puerto de Santa María (Cádiz), Archivo de Tomás Osborne Gamero-Cívico, sin clasificar.

113 Véase "Minister's Journal 1883-1891", 29 de abril y 5 de mayo de 1884, ABSI, 5/1/8. 
regresando luego a Old Windsor antes de partir de Londres rumbo a Cannes". ${ }^{114}$

De los partidos de críquet disputados en Beaumont College en el mes de junio haremos mención del que enfrentó el día 2 (Lunes de Pentecostés) a un equipo de la Beaumont Union contra el del colegio y que fue ganado por los primeros. ${ }^{115}$ El sábado 21 , serán los anfitriones quienes derroten a otro equipo de antiguos alumnos en un encuentro organizado por Humphrey F. de Trafford (que trajo desde Manchester la banda de música del regimiento Lancashire Hussars Yeomanry, del que era entonces teniente). Tres días después (Blandyke) la contienda será entre el equipo anfitrión y el formado por oficiales del segundo batallón del regimiento Coldstream Guards, de guarnición en Windsor. Vencieron los militares por 19 carreras. ${ }^{116}$ Ya en julio, el jueves 17 se juega $-y$ pierde - contra el Emeriti, un club integrado por antiguos alumnos de colegios católicos. Finalmente, el tradicional encuentro contra el Oratory School se saldó el día 21 con la victoria del equipo visitante. ${ }^{117}$

En el terreno académico hay que señalar el éxito obtenido en el London Matriculation por los alumnos Bernard Nicholl y Francis Xavier Russell, que se clasificaron en los puestos séptimo y decimocuarto, respectivamente, de los 534 candidatos que superaron el examen en la convocatoria de junio de $1884 .{ }^{118}$ Nicholl y Russell fueron dos de los protagonistas en la distribución de premios que tuvo lugar el jueves 31 de julio. Presidió la "exhibición académica" una vez más el obispo de Portsmouth (Dr. Virtue), a quien secundó en la entrega de premios Arthur G. Riddell (1836-1907), obispo de Northampton. En la clase de Figures resultaron premiados los españoles José Pérez-Seoane Villalobos y Juan Osborne Guezala, este en "puntos globales". Tras el almuerzo, los invitados - dos de los cuales eran lord Ashburnham y la condesa de Gomar- pudieron contemplar una serie de objetos de interés, entre los

114 Anónimo. "The Duchess of Madrid". The Slough, Eton and Windsor Observer, 17 mayo 1884: 3. Véase "Minister's Journal 1883-1891", 12 de mayo de 1884, ABSI, 5/1/8; Anónimo. "Los señores duques de Madrid". El Siglo Futuro (Madrid), 19 mayo 1884: 2. $5 / 1 / 8$.

115 Véase "Minister's Journal 1883-1891", 2 de junio de 1884, ABSI,

${ }^{116}$ Véase Ibídem, 21 y 24 de junio de 1884; Anónimo. "Military Visitors". The Slough, Eton and Windsor Observer, 28 junio 1884: 4; "Beaumont College v. Coldstream Guards", Ibídem 3.

117 Véase "Minister's Journal 1883-1891", 17 y 21 de julio de 1884, ABSI, 5/1/8; "Ignotus" [Bowring, W.]. 1926: 14-15.

118 Véase "Minister's Journal 1883-1891", 12 de julio de 1884, ABSI, 5/1/8; Anónimo. "Beaumont College, Old Windsor". The Slough, Eton and Windsor Observer, 19 julio 1884: 3. 
que se encontraba el retrato de la reina Victoria regalado al colegio como recuerdo de su visita de marzo de $1882 .{ }^{119}$ Quien no estuvo presente en este acto académico fue don Jaime de Borbón, pues dos días antes había salido de viaje con el P. Hayes hacia Venecia, donde los duques de Madrid "han reunido este verano gran número de invitados, españoles y franceses, teniendo algunos de ellos que alojarse en los hoteles por ser insuficiente el palacio Loredán para contener a todos". ${ }^{120}$ Tras solo un curso de permanencia, dejará ahora definitivamente el colegio el gibraltareño (descendiente de españoles) Carlos Larios Sánchez de Piña. ${ }^{121}$

\section{Curso 1884-1885}

Al comenzar el nuevo curso a mediados de septiembre de 1884 seguían en el colegio los siguientes cinco alumnos españoles o de ascendencia española: Juan Osborne Guezala, José Pérez-Seoane Villalobos, D. Jaime de Borbón, Fernando Osborne Guezala y Roberto Osborne Guezala. Los dos primeros coinciden en la clase de Rudiments y los otros tres en la de Figures. No se matricularán nuevos alumnos españoles o de ascendencia española durante este curso. Don Jaime se incorpora —con el P. Hayes- el 16 de septiembre. ${ }^{122}$ Había pasado la

119 Véase "Minister's Journal 1883-1891", 31 de julio de 1884, ABSI, 5/1/8; Annual Distribution of Prizes 1873-1914, 31 de julio de 1884, ABSI, 5/2/19A; Anónimo. "Speech Day at Beaumont College". The Times (Londres), 1 agosto 1884: 5 .

${ }^{120}$ El Siglo Futuro (Madrid), 4 agosto 1884: 2. Véase "Minister's Journal 1883-1891", 29 de julio de 1884, ABSI, 5/1/8.

121 No tenemos datos sobre la trayectoria de Carlos Larios inmediatamente posterior a su salida del colegio. Sabemos que en 1899 vivía en Connaught House, la casa familiar de Gibraltar, residencia que compartirá con la mansión de estilo inglés edificada entre 1901 y 1903 en Guadacorte (Los Barrios). El menor de los hermanos Larios se casará el 16 de abril de 1909 en Madrid- con María Mitjans Manzanedo (1867-1940), primera condesa del Rincón (1909), cuyos hermanos Francisco y Juan Manuel habían sido alumnos de Beaumont College. Carlos Larios, que poseía la Gran Cruz del Mérito Militar, fue diputado liberal por Cádiz (1916-1917) y mayordomo de semana del rey Alfonso XIII. Hábil yóquey, cazador, jugador de críquet y de polo. Falleció sin descendencia en Madrid el 15 de mayo de 1950. Véase López Zaragoza, L. 1899. Guía de Gibraltar y su Campo: 63. Cádiz: J. Benítez; Moore, S. 1984. "Seated in English Style. The Country Pursuits of a Spanish Family". Country Life 175: 1572-1574; Aranda Bernal, A. 2004. "De Miramar a Guadacorte. La influencia inglesa en la arquitectura de recreo del Campo de Gibraltar". Reales Sitios 161: 57-61.

122 Véase "Minister's Journal 1883-1891", 16 de septiembre de 1884, ABSI, 5/1/8. 
última parte de las vacaciones de verano con sus padres y hermanas junto a su tía abuela -"desconsolada viuda de Enrique V"123 - la condesa de Chambord, María Teresa de Austria-Este (1817-1886), en Frohsdorf, "donde fui a cazar perdices con Papa y me divertí mucho". ${ }^{124}$

Un total de 32 jesuitas componen la comunidad de Beaumont College: 11 sacerdotes, 11 escolares y diez hermanos coadjutores. Desde el 28 de agosto de 1884, el colegio tiene nuevo rector: el antiguo P. ministro, Frederick O'Hare, de 34 años, nacido en Market Rasen (Lincolnshire, Inglaterra). El prefecto de disciplina es ahora el P. Henry Parker (1849-1922), mientras que el P. Hogan pasa a ser uno de sus tres ayudantes. Como superior de la domus praeparatoria se nombra al $\mathrm{P}$. Thomas McMullin (1851-1928), que suple la ausencia del P. Lynch (tercera probación) durante este curso. ${ }^{125}$ El antiguo alumno Wilfrid Bowring opina que el P. O'Hare "podía ser alegre, siendo hosco, pero en general su actitud era rígida y poco comprensiva" y que los siete años de su rectorado "siempre se han considerado como una época, un periodo de prosperidad alrededor del cual se ha formado un halo". ${ }^{126}$

El 2 de diciembre se recibe en el colegio la visita del capitán inglés George Merry, veterano de la primera guerra carlista (1833-1840), que era portador de unas casullas blancas como regalo de la duquesa de Madrid. Cuatro días después se juega al fútbol (association football) contra un equipo de antiguos alumnos, entre los que se encontraban los hermanos Humphrey y Charles Edmund de Trafford. Es probable que Juan Osborne Guezala no estuviese presente en los actos del día de la Inmaculada, pues cogió por entonces la varicela. Don Jaime de Borbón se marcha a Italia de vacaciones de Navidad con el P. Hayes el 18 de diciembre (el mismo día que José Pérez-Seoane). ${ }^{127}$ No verá a su padre en esta ocasión, pues don Carlos se había embarcado en Trieste el primero de ese mes para la India y Egipto y no regresará de su viaje hasta el 30 de marzo de $1885 .{ }^{128}$

${ }^{123}$ El Siglo Futuro (Madrid), 8 octubre 1884: 1.

${ }^{124}$ Carta de D. Jaime de Borbón a lord Bertram Ashburnham, fechada en Beaumont College (Old Windsor) el 1 de octubre de 1884. Lewes (Inglaterra), East Sussex Record Office, Correspondence ASH-2905, 1881-1912.

125 Véase "Beaumont status from beginning: compiled by Mr. Sexton", ABSI, PO/2, ff. $2^{r}$ y $4^{r}$.

126 [Bowring, W.]. c. 1930: galerada 3.

127 Véase "Minister's Journal 1883-1891", 2, 6, 10, 8 y 18 de diciembre de 1884, ABSI, 5/1/8.

128 Véase El Siglo Futuro (Madrid), 10 abril 1885: 1; Martín Melgar, F. 1940: 124-135; López-Sanz, F. 1969. Carlos VII. El rey de los caballeros y el caballero de los reyes: 55. Pamplona: Editorial Gómez. 
El 12 de febrero de 1885 (Blandyke) se jugará un Grand Match y habrá una representación de The Wrong Man, adaptación del famoso melodrama francés Le Courrier de Lyon (1850). El lunes y martes de carnaval (16 y 17 de febrero) vuelven las funciones teatrales a Beaumont, con la puesta en escena del Richard III de Shakespeare -el segundo día, ante unos 200 invitados-por parte del grupo de teatro de los antiguos alumnos. ${ }^{129}$ EI P. ministro (George Dover) anotó el jueves 19 en su diario la llegada del general Antonio Guzmán Blanco (1829-1899), expresidente de la República de Venezuela, a la sazón ministro plenipotenciario en Londres. Aunque el general Guzmán tenía tres hijos en el internado jesuita (Antonio, Bernardo y Andrés), el objeto de su visita era principalmente ir a ver al alumno Carlos Clemente Crespo (hijo del entonces presidente venezolano, general Joaquín Crespo Torres), que estaba muy enfermo. ${ }^{130}$

El 4 de abril (Sábado Santo) comienzan las vacaciones de Semana Santa, que el $P$. Hayes y don Jaime pasarán en Londres esta vez. Acompañados por el capitán Merry, ambos harán el día 9 una visita al Banco de Inglaterra, donde se les mostró un billete de $£ 1000$ firmado por don Carlos en 1876. ${ }^{131}$ En vista de que se había presentado una epidemia de escarlatina en el colegio, se decidió dar a las familias la opción de posponer la fecha de regreso de las vacaciones. Como el 16 de abril faltaba por incorporarse la mitad de los 75 alumnos que se habían marchado, fue necesario enviar una circular reclamándolos. ${ }^{132} \mathrm{El}$ lunes 25 de mayo (Pentecostés) tiene lugar el partido de críquet contra la Beaumont Union, mientras que tres días después (Blandyke) el equipo rival será uno formado por miembros de la comunidad jesuita. La duquesa de Madrid viene a visitar a su hijo y vuelve a alojarse con lady Bulkeley en Pelling Place entre el 28 y el 31 de mayo. ${ }^{133}$ En el Blandyke de junio (día 25) se pierde al críquet contra el club "Ne'er do Wells". Uno de los jugadores del equipo de Beaumont fue Juan Osborne Guezala, quien contará a su hermano Tomás en una carta cómo había transcurrido el partido: "Yo por mala suerte no me lucí; tube ( $\mathrm{sic}$ ) nada más que un wicket y hera (sic) bueno y también en la primera over la tercera pelota,

129 En estas festividades estuvo presente el obispo de Portsmouth. Véase "Minister's Journal 1883-1891", 12, 16 y 17 de febrero de 1885, ABSI, 5/1/8; "Shrovetide at Beaumont". The Tablet (Londres), 21 febrero 1885: 311; Digby Beste, S.J., K. 1908: 395.

130 Véase "Minister's Journal 1883-1891", 19 de febrero de 1885, ABSI, $5 / 1 / 8$.

131 Véase Ibídem, 4 de abril de 1885; The Tablet (Londres), 11 abril 1885: 582.

132 Véase "Minister's Journal 1883-1891", 6, 16 y 17 de abril de 1885.

${ }^{133}$ Véase Ibídem, 25, 28 y 31 de mayo de 1885. 
porque hice como si fuese a volear muy fuerte y fue muy despacio y como no estaba preparado me lo saqué después que hizo 26 carreras". ${ }^{134}$ El día 9 de julio, el Emeriti Cricket Club gana al equipo del colegio por 131 a 112, a pesar de que entre los jugadores de Beaumont había dos jesuitas a quienes Juan Osborne calificó en la citada carta como "muy buenos": el P. Henry Parker — prefecto de disciplina - y el maestrillo de la escuela preparatoria Aloysius Guibara (1862-1908). ${ }^{135} \mathrm{EI}$ equipo de Beaumont sufrirá una nueva derrota el jueves 23 de julio, esta vez ante el once titular del Oratory School, que llegó acompañado del director del colegio, P. John Norris (1843-1911). ${ }^{136}$

La Academia de fin de curso tuvo lugar el martes 4 de agosto de 1885 en el teatro del colegio. Presidió el acto otro año más el Dr. Virtue, obispo de Portsmouth, que distribuyó los premios. El español José Pérez-Seoane Villalobos, de la clase de Rudiments, volvió a ser galardonado. Uno de los alumnos más premiados ese día fue el dublinés Henry Jury, prefecto de la congregación mariana y jugador del equipo titular de críquet. Además de recibir el primer premio -medalla de plata- de la clase de Rhetoric, el premio de la Asociación de Antiguos Alumnos en Classical Honours (£5) y de conseguir la máxima puntuación en Doctrina Cristiana, Jury obtuvo las $£ 25$ de la Inter-Collegiate Competition, concedidas por el provincial de la orden al estudiante de los cuatro colegios jesuitas de Inglaterra que quedara mejor clasificado en el London Matriculation. Unos 280 comensales —lord Ashburnham y lady Bulkeley entre ellos - asisten al almuerzo posterior, que amenizó la banda de los Seaforth Highlanders. ${ }^{137}$ El rector O'Hare partirá el sábado

${ }^{134}$ Carta de Juan Osborne Guezala a Tomás Osborne Guezala, fechada en Beaumont College (Old Windsor) el 28 de junio de 1885. El Puerto de Santa María (Cádiz), Archivo de Tomás Osborne Gamero-Cívico, sin clasificar. Véase "Minister's Journal 1883-1891", 25 de junio de 1885, ABSI, 5/1/8.

${ }^{135}$ Véase "Minister's Journal 1883-1891", 9 de julio de 1885, ABSI, 5/1/8; "Prefect's Journal 1883-1894", 9 de julio de 1885, ABSI, 5/1/5.

136 Véase "Minister's Journal 1883-1891", 23 de julio de 1885, ABSI, 5/1/8; "Ignotus" [Bowring, W.]. 1926: 16-17.

137 Véase "Minister's Journal 1883-1891", 4 de agosto de 1885, ABSI, 5/1/8; Annual Distribution of Prizes 1873-1914, 4 de agosto de 1885, ABSI, 5/2/19A; Anónimo. "Speech Day at Beaumont College". The Times (Londres), 5 agosto 1885: 8; The Tablet (Londres), 8 agosto 1885: 231. El número de internos que había en el colegio al terminar el curso 1884-1885 estaría en torno a los 180. Fue la cifra más alta que se alcanzó ese año académico, durante el cual ingresaron 48 alumnos y salieron 46. El dato lo tomamos de una hoja suelta que se conserva en $\mathrm{ABSI}, \mathrm{PE} / 5$. 
8 de agosto con el grueso de la comunidad jesuita para Teignmouth, en Devonshire, donde pasarán 15 días de vacaciones. ${ }^{138}$

\section{Curso 1885-1886}

Llegamos al último de los seis cursos que comprende nuestro estudio. Siguen matriculados en el colegio Juan Osborne Guezala, José Pérez-Seoane Villalobos, D. Jaime de Borbón, Fernando Osborne Guezala y Roberto Osborne Guezala. Los dos primeros han pasado a la clase de Grammar y los tres restantes a la de Rudiments. En la comunidad jesuita — compuesta por 32 miembros - se producen algunos cambios: el P. William Kenny es sustituido por el P. George Huggins (1843-1918) como viceministro, mientras que el $P$. Lynch reasume el cargo de superior de la escuela preparatoria, siendo destinado a Stonyhurst el P. Thomas McMullin. Para impartir Matemáticas, Física y Química llega el jesuita londinense Joseph Blackett (1858-1936). ${ }^{139}$

El Padre espiritual, James Hayes, había regresado a Beaumont con don Jaime el 18 de septiembre de 1885, tras dos días de viaje desde Viareggio. ${ }^{140}$ Don Carlos - con doña Margarita y sus hijas Blanca y Elvira - se embarca entonces en Trieste para acompañar hasta Corfú a sus cuñados los condes de Bardi, Enrique de Borbón-Parma (1851-1905) y Aldegonda de Braganza (1858-1946). Pero retornan pronto a Italia los duques de Madrid, "que, teniendo concentrada toda su atención en los sucesos de España, siguen con patriótica ansiedad las diversas fases del conflicto de las Carolinas y no quieren estar alejados de los centros de noticias". ${ }^{141}$ El 12 de noviembre, jueves, José Pérez-Seoane Villalobos fue uno de los alumnos confirmados por el obispo de Portsmouth (tomó el nombre de "Salvador"). Al día siguiente, festividad de san Estanislao, Mons. Virtue concelebró una misa pontificial, durante la que el P. Daniel Considine (1849-1922) —llegado la víspera desde Roehampton- hizo un elocuente panegírico del santo jesuita. Ya por la tarde, varios alumnos entretuvieron a sus compañeros y a algunas señoras con una selección de números de The Mikado, la exitosa ópera cómica de Gilbert y Sullivan estrenada en Londres en marzo de ese año. Después, el Sr. Henry

138 Véase "Minister's Journal 1883-1891", 8 y 24 de agosto de 1885, ABSI, 5/1/8.

139 Véase Ibídem, 23 de septiembre de 1885; "Beaumont status from beginning: compiled by Mr. Sexton", ABSI, PO/2, f. $2^{r}$ y $4^{r}$.

140 Véase "Minister's Journal 1883-1891", 18 de septiembre de 1885, ABSI, 5/1/8.

${ }^{141}$ El Siglo Futuro (Madrid), 23 septiembre 1885: 1. 
Evans ("Evanion"), "un prestidigitador y ventrílocuo muy inteligente, divirtió mucho a todos con sus magníficos trucos". ${ }^{142}$

El sábado 5 de diciembre tiene lugar un partido de association football contra los jugadores de la Asociación de Antiguos Alumnos, que gana el equipo anfitrión por dos goles de ventaja. ${ }^{143}$ Diez días después, don Jaime de Borbón escribirá a lord Ashburnham para agradecerle el envío de unos faisanes - que ha compartido con sus compañeros de mesa- y decirle que espera con impaciencia la llegada de las vacaciones, "pues me parece que hace un siglo que no he estado en Viareggio. Creo que saldremos el 22 de Beaumont, pero aun no estamos seguros". ${ }^{144}$ No hace don Jaime en esta carta comentario alguno sobre la difícil coyuntura política por la que atravesaba España a raíz de la prematura muerte - el 25 de noviembre de 1885- del rey Alfonso XII. Su viuda, la regente María Cristina de Habsburgo (1858-1929), había prestado el 27 de noviembre el juramento constitucional de fidelidad al "heredero de la Corona constituido en la menor edad" ante el nuevo Gobierno presidido por el liberal Práxedes Mateo-Sagasta (1825-1903). A pesar de que la infanta María de las Mercedes de Borbón (1880-1904) era - como princesa de Asturias - la heredera al trono de España, se decidió no proclamarla reina, dada la situación de incertidumbre creada por el embarazo de doña María Cristina, "toda vez que, caso de ser varón el fruto del nuevo parto, a él correspondería la sucesión de la Corona". ${ }^{145}$ A sus 15 años, el hijo del duque de Madrid se había convertido involuntariamente en uno de los protagonistas de una intriga política fraguada —al parecer - en la corte de Austria, que pretendía solucionar el pleito dinástico en España mediante el casamiento de don Jaime con la princesa de Asturias en 1896, si en la primavera de 1886 la regente no daba a luz a un varón. ${ }^{146} \mathrm{El}$ expresidente conservador

142 The Tablet (Londres), 21 noviembre 1885: 830. Véase "Minister's Journal 1883-1891", 12 y 13 de noviembre de 1885, ABSI, 5/1/8; "Beaumont First Communions, Confirmations, etc.", 12 de noviembre de 1885, ABSI, $5 / 2 / 17$. $5 / 1 / 8$

${ }^{143}$ Véase "Minister's Journal 1883-1891", 5 de diciembre de 1885, ABSI,

${ }^{144}$ Carta de D. Jaime de Borbón a lord Bertram Ashburnham, fechada en Beaumont College (Old Windsor) el 15 de diciembre de 1885. Lewes (Inglaterra), East Sussex Record Office, Correspondence ASH-2905, 18811912. De hecho, don Jaime saldrá para Italia con el $P$. Hayes el lunes 21 de diciembre. Véase "Minister's Journal 1883-1891", 21 de diciembre de 1885, ABSI, 5/1/8.

145 Martín Alonso, A. 1914. Diez y seis años de Regencia (María Cristina de Hapsburgo-Lorena) (1885-1902): 9. Barcelona: Vda. de Luis Tasso.

146 Véase The Standard (Londres), 8 diciembre 1885: 5; Anónimo. "Political Prospects in Spain". The Daily News (Londres), 8 diciembre 1885: 5. 
Antonio Cánovas del Castillo (1828-1897) repudió el proyecto, calificándolo como "un absurdo y un insulto al pueblo español". ${ }^{147}$ Don Carlos reaccionó enviando un comunicado a diversos periódicos británicos, en el que aseguraba que las noticias sobre una posible fusión dinástica eran "cuando menos prematuras" y que él nunca consentiría una alianza que pudiera interpretarse como "una renuncia por su parte a sus propios derechos o un reconocimiento de cualesquiera otras pretensiones al trono de España". ${ }^{148}$

Don Jaime y el P. Hayes cruzan el Canal de la Mancha desde Calais el 13 de enero de 1886 y llegan por la tarde a Old Windsor. Un total de 108 alumnos regresaron ese día al colegio. ${ }^{149}$ Será la primera noche que pase en el internado el mexicano José Dionisio Tiburcio de Velasco, a quien debemos incluir en nuestro elenco por tratarse -como veremos- de un muchacho de ascendencia española. En el registro de Beaumont College se dice que José Dionisio había venido al mundo en México (a secas) el 14 de agosto de 1870 y que había estado escolarizado en un establecimiento -no especificado- de Canterbury (Kent) durante un año. Sus conocimientos consistían en "César \& Cicerón. Verbos griegos. Francés. Fracciones". Pero como sus nociones de inglés debían de ser escasas, se le destina -a pesar de sus 15 años- a la clase de Figures, donde tendrá como profesor al novel maestrillo James Nicholson (1855-1934). ${ }^{150}$ José Dionisio de Velasco, nacido en Puebla ( $n .^{\circ} 11$ de la calle de Mesones), era el quinto hijo (segundo varón) de los 11 habidos del matrimonio -1863 - entre Dionisio José de Velasco Carballo (Veracruz 1836-Puebla 1901) y Josefa Almendaro Ituarte (Puebla 1848-Puebla 1880). Por línea paterna, José Dionisio de Velasco Almendaro descendía del santanderino Dionisio José de Velasco Gutiérrez del Valle (Santayana 1795-La Habana 1861), quien hacia 1813 había emigrado a México, estableciéndose como comerciante de importación en Veracruz. En 1827 se casaría con la mexicana Pilar Carballo Romay (1803-1862), miembro de una familia de cosecheros de algodón veracruzana. Nombrado vicecónsul de España en dicha ciudad

147 Anónimo. "The Late King of Spain", The Standard (Londres), 12 diciembre 1885: 5 .

148 The Times (Londres), 15 diciembre 1885: 9.

149 Véase "Minister's Journal 1883-1891", 13 de enero de 1886, ABSI, 5/1/8; The Daily News (Londres), 15 enero 1886: 6. Durante las Navidades, don Jaime pudo ver a su abuelo don Juan, que se presentó inesperadamente en Viareggio. De allí se trasladaron a Venecia para pasar el día de Reyes en familia (excepto Elvira y Alicia, que habían regresado a su colegio de Florencia). Véase El Siglo Futuro (Madrid), 22 enero 1886: 2.

150 Véase "Register of boys admitted into St. Stanislaus' College, Beaumont”, ABSI, 5/3/31B. 
portuaria en $1837,{ }^{151}$ Dionisio $\mathrm{J}$. de Velasco fundaría dos años después en la ciudad de Puebla, a orillas del río Atoyac, la fábrica de hilados y tejidos El Patriotismo Mexicano. Tras fallecer el Sr. Velasco, sus cinco hijos varones constituyen en 1863 la sociedad Velasco Hermanos, correspondiendo al mayor de ellos, Dionisio J. de Velasco Carballo, la administración de la fábrica de Puebla.

El padre del alumno que nos ocupa, "persona rica, profundamente cristiana y bien relacionada", ${ }^{152}$ había estudiado con los jesuitas en St. John's College (Fordham, Nueva York) entre 1848 y 1851. Ayudado por el P. Francisco Javier Cavalieri, S.J. (1821-1878), Dionisio J. de Velasco Carballo propiciaría la fundación -en el centro de Puebla, el 15 de enero de 1870- del Colegio Católico del Sagrado Corazón de Jesús, donde hacia 1875 sería admitido como interno el mayor de sus hijos varones, Francisco de Velasco Almendaro (1866-1951). ${ }^{153}$ Las deudas contraídas por el Sr. Velasco Carballo como administrador de El Patriotismo Mexicano no impidieron que, por recomendación facultativa, se embarcara en Veracruz el 8 de febrero de 1883 con todos sus hijos rumbo a Europa, llegando un mes después a Santander. Es probable que José Dionisio iniciara ese año estudios en el colegio jesuita de NotreDame de la Paix (Namur, Bélgica), institución en la que ingresará su hermano Francisco a finales de noviembre de $1883 .{ }^{154}$ Desde abril de 1885, al menos, se encontraban los hermanos Francisco y José Dioniso de Velasco en Inglaterra, como alumnos de St. Mary's College, el

${ }^{151}$ Primer representante de la Corona española tras la Independencia de México, el Sr. Velasco acogió a muchos compatriotas en su casa de Veracruz, por lo que fue conocido como "el padre de los españoles". En abril de 1856, tres años antes de que el Gobierno de Benito Juárez (1806-1872) retirara el exequátur a Velasco, el diplomático Emilio Alcalá-Galiano Valencia (1831-1914) se alojó "a ruego suyo en la espaciosa casa del acaudalado Vicecónsul de España". Casa Valencia, conde de. 1898. Recuerdos de la juventud. Mis dos viajes a América: 145. Madrid: Establecimiento Tipográfico de Fortanet. Véase G. de Arboleya, J. 1861. España y Méjico. Compendio de Historia Internacional, t. I: 267. Habana: Imprenta "La Cubana"; Sáinz de los Terreros, M. 1893. El muy noble y leal valle de Soba: 255-256. Madrid: R. Velasco.

152 Palomera, E. J. 1999. La obra educativa de los jesuitas en Puebla (1578-1945): 262. México/Puebla: Universidad Iberoamericana/Instituto Oriente.

153 Véase de Velasco, F. 1946. Autobiografía: 15-16. Puebla: Editorial Bohemia Poblana; Palomera, E. J. 1999: 264-265; Leicht, H. 1980. Las calles de Puebla. Estudio histórico: 390. Puebla: Municipio de Puebla.

${ }^{154}$ Véase de Velasco, F. 1946: 17. 
collège-en-exile establecido en 1880 por los jesuitas franceses en una mansión - Hales Place- próxima a Canterbury. ${ }^{155}$

En el Blandyke de marzo de 1886 (jueves 4) se juega un Grand Match de fútbol. Durante el carnaval, entre el 7 y el 9 de ese mes, los alumnos representan The Baronet and the Butterman, una versión de la comedia de Henry J. Byron Our Boys (1875), mientras que el grupo de teatro de los antiguos alumnos dramatizó la novela Guy Mannering (1815), de sir Walter Scott. Entre las aproximadamente 230 personas que vieron esta última representación se encontraban lord Ashburnham, lady Bulkeley y Mons. Iord William Joseph Petre (1847-1893), decimotercer barón Petre de Writtle. ${ }^{156}$ El 12 de marzo, recién iniciada la Cuaresma de ese año 1886, llegan a Beaumont dos hermanos apellidados "de Uribarri", de nombre "George" y "Michel". El registro del colegio nos informa de que Jorge había nacido en Madrid el 28 de noviembre de 1875 , de que su colegio de procedencia era uno de la ciudad egipcia de Alejandría y de que no sabía nada de latín. Es destinado a la clase de Preparatory, responsabilidad de Aloysius Guibara. En cuanto a Miguel, los únicos datos que constan en el registro son el lugar y la fecha de su nacimiento (Alejandría, 30 de abril de 1877), pero es fácil deducir que fuese adscrito a la misma clase que su hermano mayor. ${ }^{157}$ El primer apellido de Jorge y de Miguel es en realidad "Gil de Uribarri", pues eran hijos de Ramiro Gil de Uribarri Ossorio (Madrid 1849-Nagasaki 1921) ${ }^{158}$ y

${ }^{155}$ El jesuita belga Charles Croonenberghs (1843-1899) vio el 12 de abril de 1885 en St. Mary's College a Francisco de Velasco Almendaro, quien le pidió "que le llevara una carta a su padre, en México". Croonenberghs, S.J., C. 1892. Trois ans dans l'Amérique septentrionale.1885, 1886, 1887. Le Canada.1885: 92. París/Lyon: Delhomme et Briguet. Datos sobre este colegio, cuyo rector — de 1881 a 1890 - fue el célebre P. Estanislao du Lac (18351909), en Buckley, S.J., C. M. 1999. When Jesuits Were Giants. Louis-Marie Ruellan, S.J. (1846-1885) and Contemporaries: 166-179. San Francisco: Ignatius Press.

156 Véase "Minister's Journal 1883-1891", 4, 7, 8 y 9 de marzo de 1886, ABSI, 5/1/8; Digby Beste, S.J., K. 1908: 395.

157 Véase "Register of boys admitted into St. Stanislaus' College, Beaumont”, ABSI, 5/3/31B.

$158 \mathrm{Su}$ padre fue el jurisconsulto y político Ramón Gil Osorio (escrito el segundo apellido con una sola "s"), que casó con Isabel de Uribarri, natural esta de Vitoria (Álava). El Sr. Gil Osorio (Villena, Alicante 1813-Madrid 1880) fue magistrado de la Audiencia de Barcelona (1847-1848), diputado a Cortes partido moderado - por los distritos alicantinos de Casas Ibáñez (1849-1851) y Sax (1857-1858), subsecretario del Ministerio de Gracia y Justicia (1857-1858), fiscal de la Audiencia de Madrid (1858-1864), fiscal togado del Tribunal Supremo de Guerra y Marina (1864-1868) y senador vitalicio (1867-1868). Se le condecoró en 1854 con la encomienda de Carlos III y en 1867 con la Gran 
de su primera esposa, Aneta Kindineco Adib (Alejandría c. 1854-Madrid $1880)^{159}$. El diplomático Ramiro Gil de Uribarri había tomado posesión como primer secretario de la legación de España en Londres el 10 de julio de 1885 -siendo ministro plenipotenciario Manuel Rancés Villanueva (1824-1897) - y desempeñará el puesto hasta su traslado a Berlín, con el mismo empleo, en el verano de $1886 .{ }^{160}$

El Padre ministro anotó en su diario el lunes 12 de abril de 1886 que uno de los tres hermanos Osborne Guezala -probablemente Juan- se encontraba muy enfermo, siendo necesario llamar a dos hermanas enfermeras para que lo atendieran. Cinco días después (Sábado de Pasión) había mejorado bastante. ${ }^{161}$ Unos 55 alumnos, don Jaime de Borbón entre ellos, se marcharán de vacaciones -bajo un fuerte aguacero- el 24 de abril (Sábado Santo). Puesto que el P. Hayes debía pronunciar el sermón del día siguiente en el colegio, D. Jaime partió solo en esta ocasión, aunque el jesuita saldrá a su encuentro el lunes 26. No hemos podido determinar si a continuación viajaron a Italia o si permanecieron en Inglaterra. ${ }^{162}$

Cruz de Isabel la Católica. Véase Anónimo. "Excmo. Sr. D. Ramón Gil Osorio". La Ilustración Española y Americana (Madrid), 22 diciembre 1880: 371.

159 Fallecida el 1 de septiembre de 1880, era hija de Jorge Kindineco y de María Verónica Adib. Los hermanos Tomás y Jorge Kindineco, acaudalados comerciantes procedentes de Anatolia $o$ del Levante mediterráneo y establecidos en Alejandría en la década de 1840, habían obtenido la naturalización como ciudadanos norteamericanos en julio de 1868. Véase Diario Oficial de Avisos de Madrid, 3 septiembre 1880: 4; Fahmy, Z. 2013. "Jurisdictional Borderlands: Extraterritoriality and 'Legal Chameleons' in Precolonial Alexandria, 1840-1870". Comparative Studies in Society and History 55/2: 305-329.

${ }^{160}$ Los empleos y destinos de Ramiro Gil de Uribarri, anteriores a 1885, habían sido los siguientes: joven de lenguas y agregado diplomático en China (1867-1871); joven de lenguas en Beirut (1871-1872) y Alejandría (1872-1874); secretario de segunda clase en San Petersburgo (1874-1875); auxiliar en el Ministerio de Estado (1875-1876); secretario de segunda clase en Constantinopla (1876-1878) y Río de Janeiro (1878-1880); secretario de tercera clase cerca de la Santa Sede, aunque prestando servicios en el Ministerio de Estado (1880-1881); secretario de primera clase en China y Siam (1881-1885). Véase "Hoja de servicio de Don Ramiro Gil de Uribarri [3 diciembre 1923]". Madrid, Archivo de la Dirección General de Costes de Personal y Pensiones Públicas, expediente 358/715/915.

161 Tomás Osborne Guezala se presentó el día 13 en el colegio para ver a su hermano. Véase "Minister's Journal 1883-1891", 12, 13, 14, 15 y 17 de abril de 1886, ABSI, 5/1/8.

162 Véase Ibídem, 24, 25 y 26 de abril de 1886. 
El siguiente alumno a quien debemos incluir en nuestro elenco es "Alfonso de Zulueta", nacido en Londres el 11 de noviembre de 1874, que ingresa el 4 de mayo de 1886. En el registro del colegio podemos leer también que Zulueta no había estado escolarizado previamente, a pesar de lo cual tenía algunas nociones de latín (declinaciones) y de francés. Su destino será la clase de Preparatory, donde coincidirá con los hermanos Gil de Uribarri. ${ }^{163}$ Alfonso María de Zulueta Petre había nacido en el domicilio familiar, n. ${ }^{\circ} 121$ de Harley Street (Marylebone). Era el primogénito y único hijo varón del "comerciante español"164 Brodie Manuel de Zulueta Willcox (Londres 1842-Londres 1918) y de Constance Petre (Writtle, Essex, 1849-Brighton 1890), casados en Londres en enero de 1873 y padres, además, de Agnes María (1876-1958), Dolores Josefina (1877-1971) y Ángela María (1879-1965). El abuelo paterno de Alfonso, Pedro José de Zulueta Madariaga (Cádiz 1809-Londres 1882), se había incorporado muy joven a la firma comercial y financiera Zulueta y C. ${ }^{\text {a }}$, cuyo control había sido asumido en 1826 desde Londres por su padre, Pedro Juan de Zulueta Ceballos (Cádiz 1784-Londres 1855), exiliado en la capital británica debido a su apoyo a la causa liberal durante el Trienio, quien obtendría en 1846 su nombramiento como senador vitalicio y un año después el título de conde de Torre Díaz. Tras conseguir la nacionalidad británica en 1836 y hacerse miembro de la Iglesia anglicana, Pedro José de Zulueta Madariaga se casó con Sophia Ann Willcox (Northampton 1813-Londres 1885), hija mayor de Brodie McGhie Willcox, uno de los fundadores de la naviera Peninsular and Oriental (P. \& O.). De este matrimonio nacieron dos hijas (Sofía Josefina y María Ana) y cuatro hijos (Brodie Manuel, Pedro Juan, José María y Francisco María). Influidos por el Movimiento de Oxford, no tardarían los cónyuges en profesar la religión católica. Pedro José de Zulueta sucedió a su padre en el título nobiliario en 1856 y fue senador hasta la Revolución de $1868 .{ }^{165}$

Brodie Manuel de Zulueta Willcox, conde de Torre Díaz desde 1883 y socio de la empresa familiar Zulueta y $C^{a}{ }^{a}$ - con sede en el $n .{ }^{\circ} 41$ de Moorgate Street- "era conocido como un hombre caritativo y devoto, que estaba relacionado con muchas instituciones católicas". ${ }^{166}$ Gentilhombre de cámara, poseía las Grandes Cruces de Isabel la Católica y de San Gregorio Magno. Francisco María (1853-1937), su

163 Véase "Register of boys admitted into St. Stanislaus' College, Beaumont", ABSI, 5/3/31B.

${ }^{164}$ Véase "General Register Office: 1881 Census Returns", Kew, Surrey, The National Archives, RG11/139, f. 84, p. 25.

165 Véase Rodríguez Caparrini, B. 2007: 17-18.

166 Anónimo. "Funerals. Count de Torre Diaz". The Times (Londres), 27 septiembre 1918: 9 . 
hermano menor y, por tanto, tío carnal de Alfonso de Zulueta Petre, se había ordenado sacerdote jesuita en septiembre de 1885. Con Francisco M. de Zulueta Willcox, alumno de Beaumont College entre 1865 y 1871, coincidirá dos cursos en Old Windsor su primo hermano Salvador de Zulueta González de la Mota (1856-1933), hijo de Antonio de Zulueta Madariaga, representante de la firma en Cádiz. Otro miembro del clan familiar había pasado por las aulas de Beaumont antes de que ingresara Alfonso de Zulueta, concretamente de 1874 a 1876: su primo hermano y homónimo Alfonso Merry del Val Zulueta (1864-1943), hijo de Sofía Josefina de Zulueta Willcox. ${ }^{167}$

El 8 de mayo de 1886, cuando Alfonso de Zulueta llevaba escasos días en el internado, ingresa el último de los alumnos españoles de este periodo 1880-1886 que analizamos. Se trata de "Arístides Fernández", nacido en La Habana (Cuba) el 7 de julio de 1874, si bien su colegio de procedencia era uno de Madrid. Arístides, que no tenía conocimientos ni de latín ni de francés, será ubicado en Elements $I$, clase que tenía asignada este curso el jesuita Henry Farmer (1849-1928). ${ }^{168}$ Arístides era el único varón de los cuatro hijos que tuvieron Arístides Fernández Fret (Sanlúcar de Barrameda, Cádiz 1844-Madrid 1910) y Susana Mathews Smith, perteneciente a una "linajuda familia inglesa", ${ }^{169}$ que fallecerá en Madrid en 1905. Cuando Arístides Fernández Mathews es admitido en Beaumont College, su padre - teniente coronel de Artillería de la Armada- estaba agregado a la legación española en Londres y pertenecía a la comisión de Marina en Inglaterra. ${ }^{170}$

El 20 de mayo de 1886 saldrá definitivamente del colegio, con 18 años, Juan Osborne Guezala, seguramente para restablecerse en EI Puerto de Santa María de la enfermedad que le aquejaba desde el mes anterior. ${ }^{171}$ Ese mismo día firmó don Carlos en Lucerna (Suiza) un solemne manifiesto a los españoles protestando contra la proclamación

167 Véase Rodríguez Caparrini, B. 2007: 17-20; Rodríguez Caparrini, B. 2011: 165-168, 214; Rodríguez Caparrini, B. 2012: 244-246, 250.

168 Véase "Register of boys admitted into St. Stanislaus' College, Beaumont”, ABSI, 5/3/31B.

${ }^{169}$ La Correspondencia de España (Madrid), 20 mayo 1905: 3. Las tres hijas del matrimonio se llamaban María, Susana y Carmen.

170 Fernández Fret sería miembro del "Comité continental de bienvenida" de la Exposición Americana de Londres (mayo-octubre, 1887). Véase Guía oficial de España 1887: 577. Madrid: M. Minuesa de los Ríos; Lowe, Ch. 1892. Four National Exhibitions in London and Their Organiser: 425. Londres: T. Fisher Unwin.

171 Véase "Minister's Journal 1883-1891", 20 de mayo de 1886, ABSI, $5 / 1 / 8$. Un resumen de la trayectoria posterior de Juan Osborne en Rodríguez Caparrini, B. 2012: 263. 
como rey del recién nacido Alfonso XIII. Poco después -23 de mayoescribe a su hijo Jaime desde Zurich abundando en esta cuestión y anunciándole la visita de "tu madre y de nuestra Blanquita". ${ }^{172}$ Efectivamente, el 8 de junio se reunirá don Jaime de Borbón en Londres con la duquesa de Madrid, con su hermana mayor y con su tía la condesa de Bardi. Allí permanecerán varios días alojados en el Hotel Pulteney (Albemarle Street), hasta que el 16 de ese mes -miércolesviajan todos a Old Windsor, acompañados por el P. Hayes: don Jaime regresa al internado, mientras que doña Margarita, su cuñada y su hija Blanca se instalan en Pelling Place hasta su marcha el sábado $19 .{ }^{173} \mathrm{El}$ rector, P. O'Hare, será invitado el 30 de junio a la inauguración oficial del cercano Royal Holloway College, una institución universitaria para mujeres. Al pasar el carruaje de la reina Victoria por la entrada principal de Beaumont College en dirección a Egham, sobre las 5 p.m., los alumnos lanzaron vítores y cantaron "God Save the Queen". ${ }^{174}$

El jueves 13 de julio regresan a España los hermanos Fernando y Roberto Osborne Guezala, concluyendo entonces la estancia en Beaumont del primero de ellos. ${ }^{175}$ El partido de críquet contra el Oratory School - programado para el día 22 (Blandyke) - tuvo que ser cancelado debido a que varios jugadores del equipo visitante se encontraban enfermos, si bien un antiguo alumno de Beaumont, Edgar Payne (1865-1933), trajo de Londres un conjunto alternativo. ${ }^{176} \mathrm{La}$

172 de Sagrera, A. 1969: 505.

173 Véase "Minister's Journal 1883-1891", 8, 9, 16 y 19 de junio de 1886, ABSI, 5/1/8; The Morning Post (Londres), 12 junio 1886: 5; La Correspondencia de España (Madrid), 16 junio 1886: 2.

174 Véase "Minister's Journal 1883-1891", 30 de junio de 1886, ABSI, 5/1/8; The Standard (Londres), 2 julio 1886: 2.

175 Véase "Minister's Journal 1883-1891", 13 de julio de 1886, ABSI, 5/1/8. Fernando Osborne Guezala se casará dos veces: en 1903, en El Puerto de Santa María, con María Teresa Febrés Vergara († 1916), con la que no tendrá hijos; en segundas nupcias - Jerez de la Frontera, 1917- con su prima Rufina Vergara Guezala (1877-1956), siendo padres de Fernando Osborne Vergara (1919-1991). Fernando Osborne Guezala morirá en Jerez de la Frontera el 20 de abril de 1923. En la necrología publicada en la Revista Portuense (21 abril 1923: 1) se dice que "hacía una vida de labor no interrumpida, colaborando con sus hermanos al próspero estado y al crédito de su negocio". Véase Eduardo Ybarra Osborne, "Notas históricas-genealógicas y heráldicas de la casa Osborne, Guezala, Böhl de Faber y Power, con algunas alianzas que han contraído" (Documento privado, Sevilla, 1929). El Puerto de Santa María (Cádiz), Archivo de Tomás Osborne Gamero-Cívico, sin clasificar, f. 17 . $5 / 1 / 8$.

176 Véase "Minister's Journal 1883-1891", 22 de julio de 1886, ABSI, 
Academia de fin de curso se celebra el martes 3 de agosto de 1886, presidida por el obispo de Portsmouth. Vuelve a recibir premio el español José Pérez-Seoane Villalobos, de la clase de Grammar. La condesa de Gomar - su madre - fue una de las aproximadamente 300 personas que asistieron al acto, entre las que se encontraban también lord Ashburnham, lady Bulkeley, el general Guzmán Blanco, el conde de Torre Díaz y el barón y la baronesa de Linden. En la clase de Rhetoric obtiene el primer premio - medalla de plata- Francis Fortescue Urquhart (1868-1934). Urquhart, futuro profesor y decano de Balliol College (Oxford), ganará asimismo el Inter-Collegiate Prize, juntamente con sus compañeros de clase Edmund Garratt Gardner (1869-1935) que llegará a ser un reputado italianista, experto en la figura de Dantey Baldwin Young (1868-1950). ${ }^{177}$

Durante el curso 1885-1886, el máximo de alumnos matriculados había llegado a $183 .{ }^{178}$ Salen definitivamente del colegio a principios de agosto de 1886 don Jaime de Borbón ${ }^{179}$ — con 16 años-y los dos hermanos Gil de Uribarri. ${ }^{180}$ La breve estancia de Arístides Fernández

177 Urquhart, Gardner y Young compartieron el premio, recibiendo $£ 7$ cada uno. Véase Ibídem, 3 de agosto de 1886; Annual Distribution of Prizes 1873-1914, 3 de agosto de 1886, ABSI, 5/2/19A; Anónimo. "Speech Day at Beaumont College". The Slough, Eton and Windsor Observer, 7 agosto 1886: 3. $\mathrm{PE} / 5$.

178 Se produjeron 49 ingresos y 43 salidas. Véase hoja suelta en ABSI,

179 Después de pasar las vacaciones de verano en Viareggio y en Frohsdorf, D. Jaime debía ingresar en el colegio de jesuitas de Feldkirch (Austria), pero estando en Munich (septiembre de 1886) cayó muy enfermo. Desaparecida la gravedad, a finales de noviembre de ese año será trasladado a Viareggio para su convalecencia. Don Jaime cursa la carrera militar en la academia de Wiener-Neustadt (1890-1893), aunque no es admitido en el ejército austríaco, por lo que se decide que haga un viaje a la India. En el verano de 1894 viaja de incógnito por España y al año siguiente visitará Marruecos. A principios de 1896 ingresa en el ejército ruso -Dragones de Lubny - como oficial de caballería, pasando en 1897 al regimiento de Húsares de Grodno (Guardia Imperial), de guarnición en Varsovia. Participó en la campaña contra los bóxeres chinos (1900) y en 1904 intervino en la guerra ruso-japonesa, de la que regresa como comandante. A la muerte de su padre en 1909 se convierte en el Jaime III —segundo duque de Madrid- de los carlistas y abandona el ejército del zar Nicolás II, quien le confiere el grado de coronel honorario de su guardia. Don Jaime de Borbón no llegó a casarse y falleció sin descendencia en París el 2 de octubre de 1931. La biografía de D. Jaime entre 1909 y 1931 puede seguirse en Ferrer, M. 1960. Historia del tradicionalismo español, t. XXIX. Sevilla: Editorial Católica Española.

180 Jorge Gil de Uribarri Kindineco continuó sus estudios en el Colegio Universitario de Namur (Bélgica), durante cinco años. Los completó en el Instituto Provincial de Guadalajara, donde en enero de 1895 obtuvo el grado de bachiller. Se matriculó después como alumno libre en la Facultad de Derecho 
Mathews en el internado jesuita concluirá en diciembre de $1886 .^{181}$ Roberto Osborne Guezala ${ }^{182}$ y José Dionisio de Velasco Almendaro ${ }^{183}$

de la Universidad Central, pero no llegó a licenciarse. Fallecerá en Barcelona en marzo de 1899. Véase "Expediente del Grado de Bachiller de D. Jorge Gil de Uribarri y Kindineco". Madrid, Archivo Histórico Nacional, Universidades, 7231; "Expediente del alumno Gil de Uribarri y Kindineco, D. Jorge". Madrid, Archivo Histórico Nacional, Universidades, 4138, expediente 14; La Vanguardia (Barcelona), 21 marzo 1899: 2.

En cuanto a su hermano Miguel, sabemos que el 30 de marzo de 1897, con 19 años, se embarcó — sin consentimiento paterno- para Cuba como soldado voluntario. Enfermo de reuma, ingresa en el Hospital de Beneficencia de La Habana, donde fallece el 11 de junio de 1897. Véase Archivo General Militar de Segovia, sección 1. a , legajo J-307.

181 Volvemos a tener noticias de él en agosto de 1892, cuando con 18 años ingresa en la Academia General Militar de Toledo. Al año siguiente causa alta en la Academia de Ingenieros (Guadalajara), en cuyo cuerpo alcanzará en 1920 el empleo de teniente coronel. Tras la proclamación de la Segunda República pasa a la situación de retirado. En diciembre de 1904 o enero de 1905 había contraído matrimonio con Eladia Vallespín Zayas (nacida en Barcelona en 1888), con la que tuvo al menos cinco hijos: Arístides, Ricardo, Carlos, Eladia y María. En noviembre de 1939, Eladia Vallespín residía en Madrid y estaba viuda de Arístides Fernández Mathews. Véase "Hoja de Servicios de Don Arístides Fernández Mathews". Archivo General Militar de Segovia, sección 1. ${ }^{\text {, }}$ legajo F-332; Diario Oficial del Ministerio del Ejército (Madrid), 14 noviembre 1939: 306.

182 Se casará en 1895, en Sevilla, con María Vázquez de Pablo, siendo padres de nueve hijos. Fallecida su primera mujer en 1911, Roberto Osborne contrae nuevo matrimonio con María Teresa Vázquez de Pablo (1875-1949), su cuñada, de la que no tuvo descendencia. Con su hermano Tomás, Roberto Osborne Guezala funda la fábrica de cerveza sevillana La Cruz del Campo, inaugurada en 1904. En 1926 creará en El Puerto de Santa María la empresa Conservas Sur. Roberto Osborne fallece en Sevilla el 11 de abril de 1937. Véase Eduardo Ybarra Osborne, "Notas históricas-genealógicas y heráldicas de la casa Osborne, Guezala, Böhl de Faber y Power, con algunas alianzas que han contraído" (Documento privado, Sevilla, 1929). El Puerto de Santa María (Cádiz), Archivo de Tomás Osborne Gamero-Cívico, sin clasificar, ff. 1722.

183 Hacia 1901, José Dionisio de Velasco era oficial del ejército mexicano (Séptimo Regimiento de Caballería). El 22 de abril de 1909 se casará, en Puebla, con Carlota Tirado Luna (1882-1943). En 1911, los hermanos Velasco Almendaro venderán la fábrica El Patriotismo Mexicano —que había estado cerrada durante una década - al hacendado e industrial Andrés Matienzo López. José Dionisio fallecerá, sin hijos, en 1946. Véase de Velasco, F. 1946: 28; Aguirre Anaya, C. 1987. Personificaciones del capital. Siete propiedades en la sociedad e industria textil de Puebla durante el siglo XIX: 46. Puebla: Universidad Autónoma de Puebla. 
permanecerán en Beaumont College otro curso completo más (18861887), mientras que José Pérez-Seoane Villalobos ${ }^{184}$ dejará el colegio tras aprobar el examen de ingreso en la Universidad de Londres en la convocatoria de junio de 1888. Finalmente, Alfonso María de Zulueta Petre, ${ }^{185}$ futuro conde de Torre Díaz (1919), saldrá en julio de 1893.

\section{CONCLUSIÓN}

Un total de 12 alumnos españoles o de ascendencia española ingresaron en Beaumont College desde septiembre de 1880 hasta agosto de 1886. El desglose por cada uno de los seis cursos es el siguiente: 1880-1881, 1 alumno; 1881-1882, 4 alumnos; 1882-1883, 1 alumno; 1883-1884, 1 alumno; 1884-1885, ningún alumno; 1885-1886, 5 alumnos. Hemos podido confirmar la nacionalidad 0 ascendencia española de todos ellos, así como identificar a la totalidad de los componentes del colectivo.

La mitad de los 12 alumnos que ingresan en el periodo estudiado lo hacen con 10-11 años. Los otros seis tienen las siguientes edades en

184 José Pérez-Seoane Villalobos ingresa -curso 1888-1889- en el University College de Londres, donde cursa la carrera de Ingeniería de Caminos. En 1896 se encuentra ya domiciliado en el n. 18 de la calle de San Pedro (Madrid), ciudad en la que un año antes se había casado con María Concepción Fernández de Salamanca Castilla († Madrid 1968). José PérezSeoane sucederá a su padre como segundo conde de Gomar en 1901. Fallecerá en Biarritz el 3 de octubre de 1904, con 32 años de edad, dejando tres hijos (Manuel, Inés y Josefa). Véase University College London. Calendar. Session 1890-1891. 1890: 323. Londres: Taylor and Francis; Charter, Supplemental Charters, By-Laws, and List of Members of the Institution of Civil Engineers. 1896: 197. Londres: Institution of Civil Engineers; de Atienza, J. 1965. "Grandezas y títulos del reino concedidos, rehabilitados y autorizados por S. M. el Rey Don Alfonso XII (1875-1885)". Hidalguía 68: 63-64.

185 Cursa después estudios - seguramente de Derecho- con los PP. agustinos en el Real Colegio de Estudios Superiores de María Cristina (El Escorial) y más tarde se incorpora en Londres a la firma familiar Zulueta y C. ${ }^{a}$. Nombrado gentilhombre de cámara en 1898. Alfonso María de Zulueta se casará el 16 de abril de 1902, en Cádiz, con su prima Ana María Ruiz Tagle Zulueta († Londres 1970), siendo padres de Alfonso Manuel de Zulueta Ruiz Tagle, sacerdote, nacido en Montagu Mansions (Londres) en 1903 y fallecido en Cádiz en 1980. Los condes de Torre Díaz pasaban largas temporadas en su cortijo de La Alcaría (Jerez de la Frontera). Alfonso M. de Zulueta Petre fallecerá el 17 de febrero de 1951, siendo enterrado en Ascot (Berkshire). Véase Burnand, F. C. (ed.). 1935. The Catholic Who's Who \& Year-Book: 495. Londres: Burns Oates \& Washbourne; Heim, B. 1983. "A Spanish English priest". Hidalguía 180: 757-763; Hart-Davis, D. 1992. "Ghosts of the forest". Country Life 186: 38-41. 
el momento de su ingreso: 8-9 años (3 alumnos), 12-13 años (2 alumnos) y 15 años (el alumno José Dionisio de Velasco). Los dos estudiantes españoles que menos tiempo permanecen en el internado -apenas cinco meses- son los hermanos Jorge y Miguel Gil de Uribarri Kindineco, mientras que las estancias más largas fueron la de Alfonso María de Zulueta Petre (los tres últimos meses del curso 1885-1886 más los siete cursos siguientes) y la de José Pérez-Seoane Villalobos (siete cursos completos). Don Jaime de Borbón permanecerá cinco cursos en Beaumont College, prácticamente el mismo tiempo que estuvieron internos los hermanos Fernando y Roberto Osborne Guezala. Rafael Romero Martínez se quedó tres años académicos y José Dionisio de Velasco no llegó a completar los dos cursos. Un solo curso estuvieron matriculados Emilio Cano Hall y Carlos Larios Sánchez de Piña. El periodo de permanencia de Arístides Fernández Mathews fue de unos 6 meses.

La docena de alumnos españoles o de dicha ascendencia que pasan por las aulas de Beaumont College en este periodo 1880-1886 viene a coincidir prácticamente con la cifra de 11 admitidos entre 1874 y 1880. Una vez más, las causas de la notable disminución numérica con respecto al lapso que va desde enero de 1869 hasta agosto de 1874 cuando ingresan 24 alumnos españoles o de idéntica ascendencia- no son siempre fáciles de determinar. Debemos recordar que a partir de la Restauración alfonsina de 1875 tuvo lugar en España la reapertura de los colegios jesuitas cerrados tras la Revolución de 1868, así como la creación de nuevos centros educativos. Cuando concluye la primera década de la Restauración, coincidiendo con la fecha terminal de nuestro estudio, eran 14 los colegios de segunda enseñanza, que "aparecen estratégicamente repartidos por casi todas las regiones de España". ${ }^{86}$ Las familias españolas que deseaban que sus hijos fuesen educados en instituciones de la Compañía de Jesús no tenían ya que enviarlos necesariamente más allá de las fronteras patrias. De hecho, menos de la mitad - cinco- de los 12 españoles o descendientes de españoles que ingresan entre 1880 y 1886 se desplazan directamente desde España: Rafael Romero Martínez (Jerez de la Frontera), José Pérez-Seoane Villalobos (Madrid), Fernando Osborne Guezala (El Puerto de Santa María), Roberto Osborne Guezala (El Puerto de Santa María) y Arístides Fernández Mathews (Madrid). De los siete restantes, uno se traslada desde Francia (don Jaime de Borbón), Carlos Larios llega desde Gibraltar, mientras que los dos hermanos Gil de Uribarri Kindineco viajan, probablemente, desde Alejandría. Emilio Cano Hall y José Dionisio de

186 Revuelta González, S.J., M. 1984. La Compañía de Jesús en la España Contemporánea, t. I, Supresión y reinstalación (1868-1883): 720. Madrid: Universidad Pontificia Comillas. 
Velasco habían sido colegiales en Inglaterra inmediatamente antes de su ingreso en Beaumont College. Por último, Alfonso María de Zulueta se incorpora desde Londres, de donde era oriundo.

\section{BIBLIOGRAFÍA}

Aguirre Anaya, C. 1987. Personificaciones del capital. Siete propiedades en la sociedad e industria textil de Puebla durante el siglo XIX. Puebla: Universidad Autónoma de Puebla.

Anónimo. 1882. "Beaumont". Letters and Notices 15: 118-125.

Anónimo. 1884. "London University Examinations". Letters and Notices 17: 71-73.

Anónimo. 1896. "Complete list of plays, acted at Beaumont from 1862 to 1896". The Beaumont Review 6: 267-269.

Anónimo. 1897. "The Queen and Beaumont", The Beaumont Review Número especial: 6-10.

Anónimo. 1925. "Obituary. Father William Heathcote". Letters and Notices 40: 64-69.

Anuario del comercio, de la industria, de la magistratura y de la administración. 1894. Madrid: Bailly-Bailliere e Hijos.

Aranda Bernal, A. 2004. "De Miramar a Guadacorte. La influencia inglesa en la arquitectura de recreo del Campo de Gibraltar". Reales Sitios 161: 52-63.

Buckley, S.J., C. M. 1999. When Jesuits Were Giants. Louis-Marie Ruellan, S.J. (1846-1885)and Contemporaries. San Francisco: Ignatius Press.

Burnand, F. C. (ed.). 1935. The Catholic Who's Who \& Year-Book. Londres: Burns Oates \& Washbourne.

Canal, J. 2010. "Incómoda presencia: el exilio de don Carlos en París", en F. Martínez, J. Canal y E. Lemus (eds.), París, ciudad de acogida. El exilio español durante los siglos XIX y XX: 85-112. Madrid: Sociedad Estatal de Conmemoraciones Culturales/Marcial Pons Historia.

Casa Valencia, conde de. 1898. Recuerdos de la juventud. Mis dos viajes a América. Madrid: Establecimiento Tipográfico de Fortanet.

Cayuela Fernández, J. 1986. "Manuel Pérez Seoane y Domingo Norzagaray, banqueros madrileños", en L. E. Otero Carvajal y Á. Bahamonde (eds.), Madrid en la sociedad del siglo XIX, vol. 1: 477-489. Madrid: Comunidad de Madrid. 
Charter, Supplemental Charters, By-Laws, and List of Members of the Institution of Civil Engineers. 1896. Londres: Institution of Civil Engineers.

Colección de leyes, decretos, acuerdos y resoluciones. 1887. San José, Costa Rica: Imprenta Nacional.

Conan Doyle, A. 2012. Memories and Adventures. Nueva York: Cambridge University Press.

Croonenberghs, S.J., C. 1892. Trois ans dans l'Amérique septentrionale.1885, 1886, 1887. Le Canada.1885. París/Lyon: Delhomme et Briguet.

de Atienza, J. 1965. "Grandezas y títulos del reino concedidos, rehabilitados y autorizados por S. M. el Rey Don Alfonso XII (18751885)". Hidalguía 68: 49-64.

de Sagrera, A. 1969. La duquesa de Madrid (Última reina de los carlistas). Palma de Mallorca: ed. de la autora.

de Velasco, F. 1946. Autobiografía. Puebla: Editorial Bohemia Poblana.

Digby Beste, S.J., K. 1908. "List of Plays Acted at Beaumont from 1862-1908". The Beaumont Review 55: 392-399.

Dudley Edwards, O. 1982. The Quest for Sherlock Holmes. Harmondsworth: Penguin.

Erice, F. 1995. Propietarios, comerciantes e industriales. Burguesía y desarrollo capitalista en la Asturias del siglo XIX (1830-1885), t. I. Oviedo: Servicio de Publicaciones de la Universidad.

Fahmy, Z. 2013. "Jurisdictional Borderlands: Extraterritoriality and 'Legal Chameleons' in Precolonial Alexandria, 1840-1870”. Comparative Studies in Society and History 55/2: 305-329.

Ferrer, M. 1959. Historia del tradicionalismo español, t. XXVI. Sevilla: Editorial Católica Española.

Ferrer, M. 1959. Historia del tradicionalismo español, t. XXVIII, vol. I. Sevilla: Editorial Católica Española.

Ferrer, M. 1960. Historia del tradicionalismo español, t. XXIX. Sevilla: Editorial Católica Española.

Gallardo Barbarroja, M. 2003. "Introducción y desarrollo del español en el sistema universitario inglés durante el siglo XIX". Estudios $\begin{array}{llll}\text { de Lingüística } & \text { del }\end{array}$ [http://ddd.uab.cat/pub/elies/elies a2003v20/index.html].

G. de Arboleya, J. 1861. España y Méjico. Compendio de Historia Internacional, t. I. Habana: Imprenta "La Cubana". 
Gordon Gorman, W. 1910. Converts to Rome. Londres: Sands \& Co.

Gruggen, S.J., G. y Keating, S.J., J. 1901. Stonyhurst. Its Past History and Life in the Present. Londres: Kegan Paul, Trench, Trübner \& Co. Nacional.

Guía diplomática de España para el año de 1865. Madrid: Imprenta

Guía oficial de España 1887. Madrid: M. Minuesa de los Ríos.

Guía oficial de España 1894. Madrid: Viuda de M. Minuesa de los Ríos. 41.

Hart-Davis, D. 1992. "Ghosts of the forest". Country Life 186: 38-

Hayes, S.J., J. 1874. "Visit to the Carlist Country". Letters and Notices 10: 121-128.

Heathcote, S.J., W. 1940. "Reminiscences of School Life in the Early Days of Beaumont", The Beaumont Review 160: 380-383.

Heim, B. 1983. "A Spanish English priest". Hidalguía 180: 757-763. Harrison.

Hertslet, E. (compil.). 1865. The Foreign Office List. Londres:

"Ignotus" [Bowring, W.]. 1926. Beaumont v. Oratory, 1867-1925. Windsor: Robert Brodie \& Son.

Leicht, H. 1980. Las calles de Puebla. Estudio histórico. Puebla: Municipio de Puebla.

Lignon-Darmaillac, S. 2004. Les grandes maisons du vignoble de Jerez (1834-1992). Madrid: Casa de Velázquez.

López-Sanz, F. 1969. Carlos VII. El rey de los caballeros y el caballero de los reyes. Pamplona: Editorial Gómez.

López Zaragoza, L. 1899. Guía de Gibraltar y su Campo. Cádiz: J. Benítez.

Lowe, Ch. 1892. Four National Exhibitions in London and Their Organiser. Londres: T. Fisher Unwin.

Martín Alonso, A. 1914. Diez y seis años de Regencia (María Cristina de Hapsburgo-Lorena) (1885-1902). Barcelona: Vda. de Luis Tasso.

Martín Melgar, F. 1940. Veinte años con don Carlos. Memorias de su secretario el conde de Melgar. Madrid: Espasa-Calpe.

Martínez Gallego, F. A. y Sanz Rozalén, V. 2006. "Villalobos Febrero, Ángel", en J. Paniagua y J. A. Piqueras (dirs.), Diccionario biográfico de políticos valencianos: 1810-2006: 596. Valencia: Institució Alfons el Magnànim. 
Melgar [Trampus], F. 1932. Don Jaime. El Príncipe caballero. Madrid: Espasa-Calpe.

Miller, H. J. 1969. "The expulsion of the Jesuits from Guatemala in 1871". The Catholic Historical Review 54/4: 636-654.

Montoto de Sedas, C. "Don Jaime. El príncipe sencillo". Semana (Madrid), 13 octubre 1959: 20-21.

Moore, S. 1984. "Seated in English Style. The Country Pursuits of a Spanish Family". Country Life 175: 1572-1574.

Naylor, R. A. 1988. Influencia británica en el comercio centroamericano durante las primeras décadas de la Independencia (1821-1851). Antigua, Guatemala/ South Woodstock, EE.UU.: CIRMA/ Plumsock Mesoamerican Studies.

Oyarzun, R. 1944. Historia del carlismo. Madrid: Editora Nacional.

Padberg, S.J., J. W. 1969. Colleges in Controversy. The Jesuit Schools in France from Revival to Suppression, 1815-1880. Cambridge, MA: Harvard University Press.

Palomera, E. J. 1999. La obra educativa de los jesuitas en Puebla (1578-1945). México/Puebla: Universidad Iberoamericana/Instituto Oriente.

Retana, W. E. 1921. Índice de personas nobles y otras de calidad que han estado en Filipinas desde 1521 hasta 1898. Madrid: Librería de Victoriano Suárez.

Revuelta González, S.J., M. 1984. La Compañía de Jesús en la España Contemporánea, t. I, Supresión y reinstalación (1868-1883). Madrid: Universidad Pontificia Comillas.

Rodríguez Caparrini, B. 2004. "El Eton católico": el internado jesuita de Beaumont (Old Windsor, Inglaterra) durante el rectorado del Padre Joseph M. Bampton, S.J. (1901-1908). Cádiz: Servicio de Publicaciones de la Universidad (edición electrónica de tesis doctoral).

Rodríguez Caparrini, B. 2007. "Alumnos españoles en el internado jesuita de Beaumont (Old Windsor, Inglaterra), 1861-1868". Archivum Historicum Societatis lesu 151: 3-37.

Rodríguez Caparrini, B. 2011. "Alumnos españoles en el internado jesuita de Beaumont (Old Windsor, Inglaterra), 1869-1874". Archivum Historicum Societatis lesu 159: 151-250.

Rodríguez Caparrini, B. 2012. "Alumnos españoles en el internado jesuita de Beaumont (Old Windsor, Inglaterra), 1874-1880". Miscelánea Comillas 136: 241-264.

Ross, S.J., W. 1895. "Annals of the Beaumont stage". The Beaumont Review 4: 150-154. 
Sáinz de los Terreros, M. 1893. El muy noble y leal valle de Soba. Madrid: R. Velasco.

Sánchez de los Santos, M. 1914. Las Cortes Españolas: las de 1914. Madrid: A. Marzo.

Tozer, B. 1945. Roving Recollections (Recollections of a Rolling Stone). Londres/ Nueva York: T. V. Boardman.

Uriarte, R. 1888. Galería poética centro-americana, t. II. Guatemala: Tipografía "La Unión".

University College London. Calendar. Session 1890-1891. 1890. Londres: Taylor and Francis.

Vilar, J. B. 2006. La España del exilio. Las emigraciones políticas españolas en los siglos XIX y XX. Madrid: Síntesis. 